\title{
Elastohydrodynamic film thickness of soft EHL contacts using optical interferometry
}

\author{
Nigel Marx*, Johan Guegan*, Hugh A Spikes* \\ * Tribology Group, Department of Mechanical Engineering, Imperial College London, UK
}

\section{KEYWORDS}

Soft EHL, elastic-isoviscous, polymer lubrication, film thickness

\begin{abstract}
Robust, chromium, semi-reflective coatings have been applied to transparent polymethylmethacrylate and polyurethane discs and this has enabled conventional, normal incidence optical interferometry to be used to measure lubricant film thickness in soft EHL conditions for the first time. High quality interferograms comparable to those obtained from coated glass discs are obtained. Measured film thickness has been compared with existing soft EHL film thickness equations obtained using computer modelling and revised central and minimum film thickness equations have been proposed. These film thickness measurements and measurement technique have applicability to our understanding of the performance and design of lubricated gears and bearings manufactured from polymeric materials.
\end{abstract}

\section{INTRODUCTION}

There is a growing use of machine components such as rolling bearings and gears made from polymeric materials. Such components are relatively easy to manufacture and low cost, as well as being chemically-inert and lightweight. Although they can often be used unlubricated, their tribological performance is generally greatly enhanced by lubricated them with a compatible oil or grease [1-3].

Because of their low elastic moduli compared to metals, lubricated polymeric components operate in the isoviscous-elastic or "soft-EHL" lubrication regime. It is clearly important to be able to predict the film thickness present in such components and several equations exist for calculating film thickness in this lubrication regime [4-9]. However, quite surprisingly, these equations have not yet been fully validated experimentally, unlike the case of piezoviscouselastic lubrication where there have been extensive studies of EHD (elastohydrodynamic) film thickness. The probable reason for this discrepancy is that it has proved difficult to 
apply optical interferometry, which is the most accurate and convenient method for measuring EHD film thickness in piezo-viscous conditions, to study soft-EHL.

This paper describes the development of a conventional optical interferometry technique to map film thickness in soft-EHL contacts and its application to test the validity of existing regression-based, soft-EHL, film thickness equations.

\section{BACKGROUND}

In full film liquid lubrication, four different hydrodynamic regimes are recognised $[4,5]$. In lubricated contacts where the two surfaces have very similar matching shapes, such as in plain journal and thrust bearings, the high degree of local conformity results in relatively low contact pressures, typically 1 to $50 \mathrm{MPa}$. Such pressures are too low to enhance the lubricant viscosity in the contact or to change the contact geometry significantly, so the prevalent lubrication regime is known as isoviscous-rigid hydrodynamic lubrication (or often simply hydrodynamic lubrication).

In non-conforming, rolling-sliding contacts between metallic and ceramic components having high elastic modulus, as present for example in most gears and rolling bearings, very high local contact pressures occur, typically 0.5 to $4 \mathrm{GPa}$. Such pressures result in local elastic deformation of the solid surfaces to form a small region of conformity and also produce a large increase in the lubricant viscosity in the contact. These two effects have a profound effect on the lubricant film thickness and friction and the resulting lubrication regime is termed piezoviscous-elastic hydrodynamic lubrication, or hard-EHL (or often simply EHL).

There are also many lubricated non-conforming contacts in engineering where one or both of the solid surfaces are made of a polymeric material and thus has relatively low elastic modulus. Typical examples are found in windscreen wipers, engineering seals, rollingbearings with polymer cages and plastic rolling bearings and gears. In these cases there is significant elastic deformation of the polymer, which produces a quite large region of local conformity. This leads to contact pressures in the range 1 to $50 \mathrm{MPa}$, which, despite being high enough to elastically deform and thus change the shape of the contact, are not sufficient to produce a significant rise in viscosity of the lubricant due to pressure. The resulting lubrication regime is known as isoviscous-elastic hydrodynamic lubrication or softEHL. It should be noted that the term "soft" in this context is maladroit since the polymer characteristic of interest is not its strength but rather its stiffness. Thus soft- and hard-EHL should really be called compliant- and stiff-EHL respectively. However in this paper we conform to popular usage and employ soft-EHL as the recognised descriptor. 
The fourth hydrodynamic regime is piezoviscous-rigid, where the contacting solids are very stiff and so show negligible elastic deformation but the lubricant viscosity does increase significantly with local pressure. This occurs rarely in practical applications but it has been suggested that it may be present in roller end-guide flanges in moderately highly loaded cylindrical tapered roller bearings [10]

Considerable numerical modelling work has been carried out to solve combinations of the Reynolds, elastic deformation and piezoviscosity equations and thus develop regression equations to predict both central and minimum film thickness in all of the above four hydrodynamic regimes [4-7]. For the circular point contact of interest to the current study, Esfahanian and Hamrock provide non-dimensional central, $H_{c}$ and minimum, $H_{o}$ film thickness equations [6];

isoviscous-rigid, $H_{c / o}=134$

piezoviscous-rigid, $H_{c / o}=5.35 g_{v}^{0.375}$

isoviscous-elastic, $H_{c}=5.08 g_{E}^{0.67}, H_{o}=3.28 g_{E}^{0.67}$

piezoviscous-elastic $H_{c}=2.55 g_{v}^{0.53} g_{e}^{0.13}, H_{o}=1.69 g_{v}^{0.49} g_{e}^{0.17}$

where $H=\left(\frac{h}{R_{X}^{\prime}}\right)\left(\frac{\bar{W}}{\bar{U}}\right)^{2}, g_{V}=\frac{\bar{G} \bar{W}^{3}}{\bar{U}^{2}}, g_{E}=\frac{\bar{W}^{8 / 3}}{\bar{U}^{2}}$, and $\bar{U}=\frac{U \eta_{O}}{E^{\prime} R_{X}^{\prime}}, \bar{W}=\frac{W}{E^{\prime} R_{X}^{\prime 2}}, \bar{G}=\alpha E^{\prime}$

$h$ is the film thickness, $U$ the entrainment or mean rolling speed, $W$ the applied load, $\eta$ the dynamic viscosity and $\alpha$ the pressure viscosity coefficient of the lubricant. The reduced radius and reduced elastic modulus are defined respectively by; $\frac{1}{R_{X}^{\prime}}=\frac{1}{R_{x 1}}+\frac{1}{R_{X 2}}$, $\frac{2}{E^{\prime}}=\frac{\left(1-v_{1}^{2}\right)}{E_{1}}+\frac{\left(1-v_{2}^{2}\right)}{E_{2}}$ where $R_{x 1}$ and $R_{x 2}$ are the radii of the two solid bodies in the entrainment direction and $E_{1}, E_{2}$ and $v_{1}, v_{2}$ are the elastic moduli and Poisson's ratios of the two bodies.

The above elastic-isoviscous equations can be reduced to;

$$
h_{c} / R_{x}{ }^{\prime}=5.08 \bar{U}^{0.66} \bar{W}^{-0.21}, h_{o} / R_{x}{ }^{\prime}=3.28 \bar{U}^{0.66} \bar{W}^{-0.21}
$$


These equations are very similar to Hamrock and Dowson's isoviscous-elastic equations which for circular contact reduce to [11];

$$
h_{c} / R_{x}{ }^{\prime}=3.3 \bar{U}^{0.64} \bar{W}^{-0.22}, \quad h_{o} / R_{x}{ }^{\prime}=2.8 \bar{U}^{0.65} \bar{W}^{-0.21}
$$

Hooke has noted that the elastic-isoviscous and elastic-piezoviscous regimes should each be divided into two regions depending upon whether the minimum film thickness occurs at the exit of the contact or in the side lobes and that for circular contacts there is a transition from the former to the latter as the pressure increases or the entrainment speed decreases [12][13]. For the elastic-isoviscous regime he provides equations to estimate the minima at both positions [12];

$$
\begin{gathered}
H_{o}(\text { exit })=2.83 g_{E}^{0.7} \\
H_{o}(\text { side })=8.55 g_{E}^{0.625}
\end{gathered}
$$

while suggesting the central film thickness to be;

$$
H_{c}=3.56 g_{E}^{0.7}
$$

These are equivalent to

$$
\begin{aligned}
& h_{o}(\text { exit }) / R_{x}{ }^{\prime}=2.83 \bar{U}^{0.6} \bar{W}^{-0.13} \\
& h_{o}(\text { side }) / R_{x}{ }^{\prime}=8.55 \bar{U}^{0.75} \bar{W}^{-0.23} \\
& h_{c} / R_{x}{ }^{\prime}=3.56 \bar{U}^{0.6} \bar{W}^{-0.13}
\end{aligned}
$$

Two methods can be used to determine the regime in which a non-conforming lubricated contact will operate. One is to use maps to demarcate the various regimes in terms of two non-dimensional variables. A second approach is simply to calculate the predicted film thickness using four equations, each applicable to a different regime. Then the equation that predicts the thickest hydrodynamic film corresponds to the regime in which the contact will operate.

Figure 1 shows a regime map for circular point contact derived from the minimum film thickness equations (1) to (4). The dashed line marks Hooke's suggested boundary between the isoviscous elastic regime where the minimum is at the exit of the contact (I-E (exit) and that where is at the sides (I-E (side)). The red, elongated trapezoid marks the region covered in this study. 


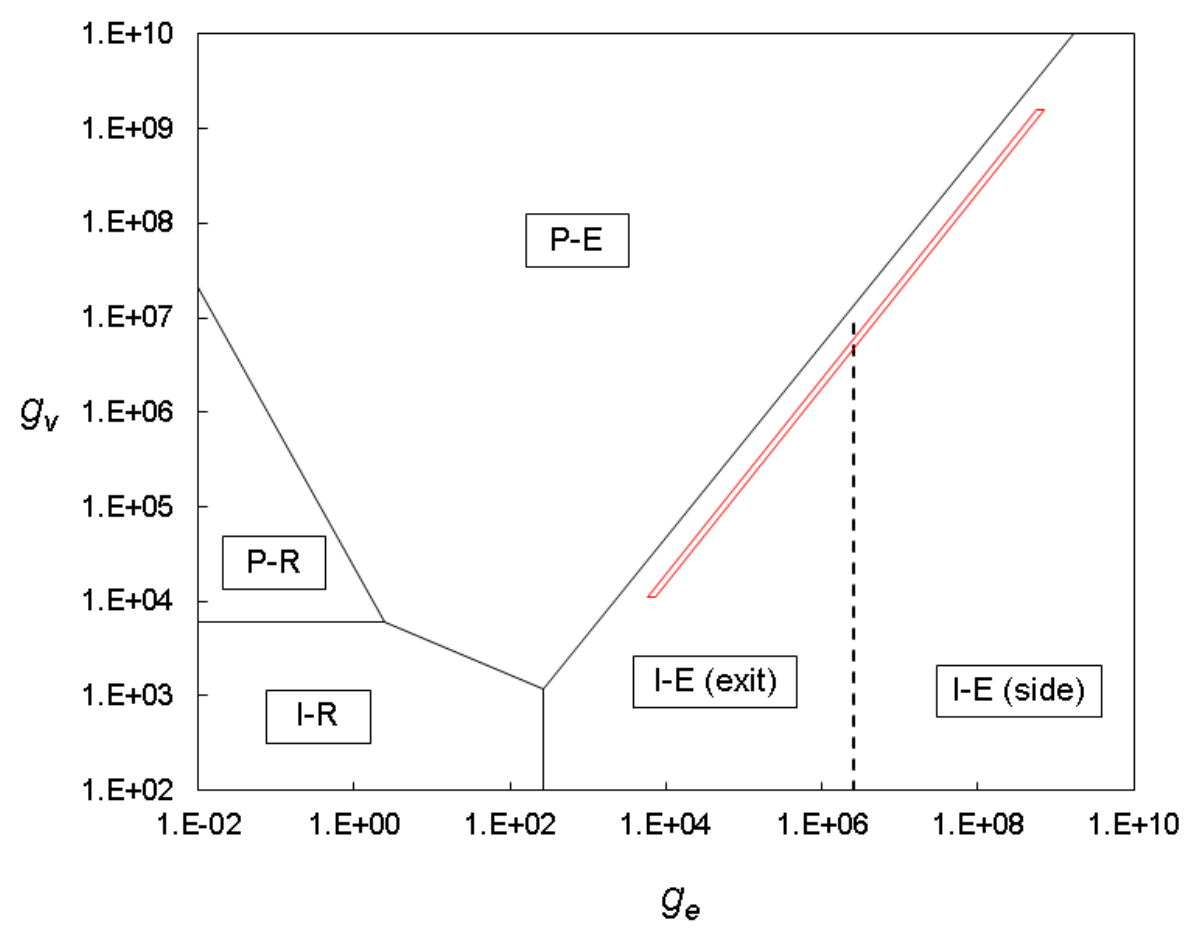

Figure 1. Hydrodynamic regime map for circular point contact adapted from [6]

The film thickness equations applicable to piezoviscous, hard-EHL contacts have been very thoroughly tested experimentally over the last 45 years, including the dependence of film thickness on entrainment speed and load [14], elastic modulus [15], viscosity [16], geometry [17] and slide-roll ratio [18]. It has been shown that in most cases these equations can be applied with reasonable confidence to predict the film thickness in engineering components operating in full film conditions. Some exceptions are at very high slide-roll ratios (where thermal effects become significant), for polymer solutions and melts (where shear thinning occurs in the contact inlet), and for complex fluids such as emulsions and greases (where compositional and structural changes take place in the lubricant during its approach to the contact). Most of this experimental validation has used the technique of optical interferometry where a hard-EHL contact is formed between a transparent flat and a reflective ball or roller and film thickness is determined from the interference between the two light beams reflected from the pair of solid surfaces that contain the lubricant film. Other experimental techniques have also been applied such as measurement of capacitance [19, 20], x-ray transmission [21], fluorescence intensity [22, 23] and ultrasonic reflection [24], but none of these methods have approached the accuracy and ease of use of the optical interference method.

In contrast to the piezoviscous-elastic regime, there has been surprisingly little systematic validation of the film thickness equations applicable to the isoviscous-elastic regime. The main reason appears to be the difficulty of applying optical interferometric techniques to 
measure film thickness in contacts where one or both of the bodies is made of polymer. Figure 2 shows a typical EHL contact as used for optical film thickness measurement. Light is shone into the lubricated contact through a transparent body, normally glass or sapphire. Some is reflected from the lower surface of the transparent disc while some passes through the lubricating film and is reflected from the reflective (usually steel) ball surface. When they recombine the two beams interfere to an extent that depends on the path difference between them, and thus the lubricant film thickness. For high quality interference the two interfering beams should have approximately the same intensity and this is achieved using a semireflective coating on the disc surface in contact with the lubricant [25]. In the absence of such a coating very little reflection takes place from the underside of the transparent disc and very low intensity interference fringes are produced. In early work this problem was overcome by using a transparent disc of very high refractive index glass [26] so as to produce a large mismatch of refractive index at the glass/lubricant interface, but this approach was rapidly superseded by the much more effective semi-reflective coating approach.

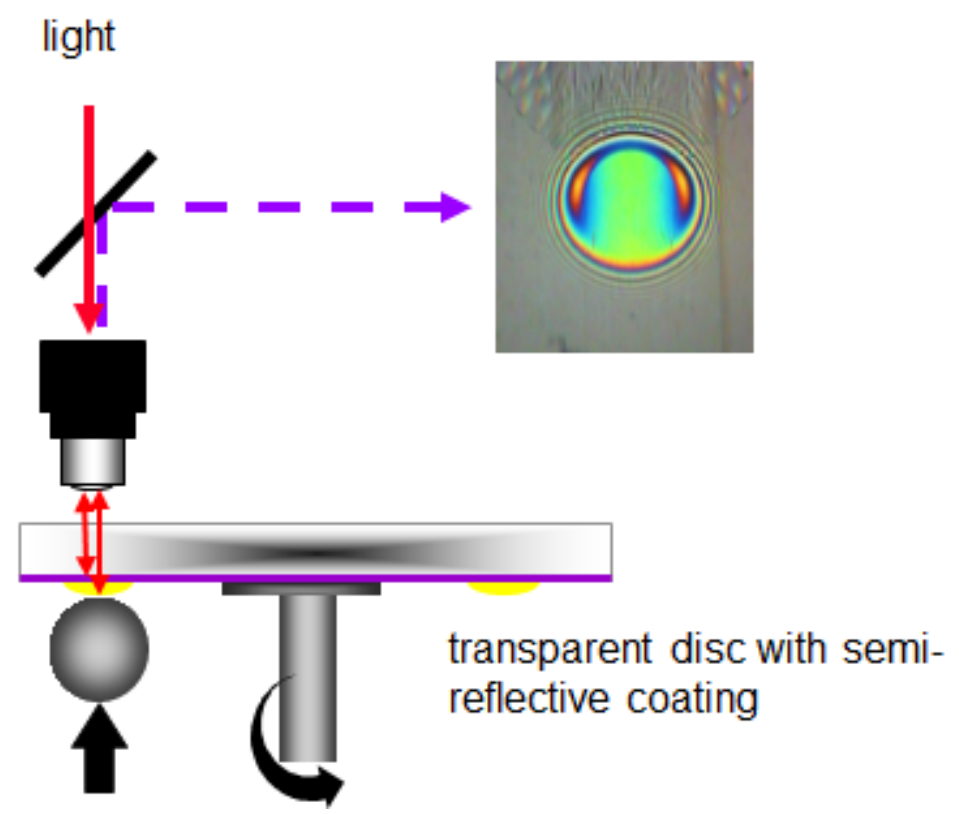

Figure 2. Optical interferometry set-up to measure lubricant film thickness

The problem when trying to apply optical interferometry to measure film thickness with polymeric bodies is that the latters' surfaces tend to be non-reflective and often quite rough. Two methods have been attempted to overcome this problem, usually in combination. One is to make the surfaces very smooth, for example by hot curing against a smooth counterface, so as to make them reasonably reflective $[27,28]$. The second is to use nonnormal incident light to avoid stray reflections and enable interference images to be obtained from the very low intensity beam reflected from the polymer surface [28-32]. These 
approaches have enabled film thickness measurements to be made, but the test set-ups have tended to be cumbersome and have not gained widespread use.

In the absence of a satisfactory optical interference method, the main technique applied to measure film thickness in soft EHL contacts has been laser induced fluorescence (LIF). In this a fluorescent dye is dissolved in the lubricant and laser light of the frequency necessary to excite this dye is shone into the contact through a transparent surface. The dye then emits light at a lower frequency and the intensity of this emission provides a measure of film thickness [22]. In a more sophisticated approach, double-dye LIF is employed in which the emission from one dye excites a second fluorescent dye present and the ratio of the emission from the two dyes is used to calculate film thickness [33]. The LIF technique has proved to be effective for measuring and mapping film thickness in soft-EHL [34, 35] but in practice is considerably less accurate than optical interferometry as used in hard-EHL. Practical problems include optical alignment and focussing, fluctuations in the laser intensity and detector sensitivity and adsorption of dye onto and into the polymer surface. Myant et al. have suggested a lower limit of film thickness measurement of $300 \mathrm{~nm}$ for the LIF technique [23] but it is best suited to measure relatively thick lubricant films, in the range 1 to $20 \mu \mathrm{m}$, and not the sub-micron range over which optical interferometry is most effective.

Clearly it would be of benefit to be able to apply conventional optical interferometry, which has proved so effective in studying hard-EHL, to measure film thickness in soft-EHL and in this paper we describe this advance. Semi-reflective coatings are applied to two transparent polymer discs and used to obtain high quality optical interference images from rolling, rollingsliding and pure sliding polymer disc-steel ball contacts.

It is not clear why this approach has not been reported previously in the literature. In the current study thermoplastic discs are used, as employed in polymer gears and bearings. These have elastic modulus typically in the range 1 to $5 \mathrm{GPa}$ and it has been found that they can be coated with robust semi-reflective coatings. It is possible that most previous attempts have focussed on elastomers such as rubber and PDMS, with much lower elastic modulus in the range 0.001 to $0.01 \mathrm{GPa}$, and that the semi-reflective coatings applied were too fragile. One early study successfully used silver coatings on PDMS but only in squeeze film conditions with no sliding present [36]. Alternatively it is possible that it was assumed that semi-reflective coating would not adhere sufficiently strongly to polymer surfaces to survive rolling-sliding contact conditions 


\section{TEST METHOD AND MATERIALS}

This study used an EHD test rig supplied by PCS Instruments (Acton, UK). When employed to measure film thickness in hard-EHL conditions, this rig usually comprises a steel ball supported on rollers and loaded upwards against the underside of a coated glass disc. The ball is half-immersed in lubricant held in a test chamber at a controlled temperature. Ball and disc are driven by two independent motors and the motor speeds, applied load and lubricant temperature are all controlled by computer. Light is shone into the contact through the glass disc and the reflected, interfered light is either passed to a spectrometer to determine the wavelength of maximum constructive interference and thus the film thickness at one location in the film or is captured directly and its interference colours compared to a colour/film thickness calibration to obtain a map of film thickness.

In the current study two transparent polymer discs were employed in place of the normallyused glass disc, one of polymethylmethacrylate (PMMA) and the other of polyurethane (PU). Their properties are listed in Table 1. The PMMA disc was cut from sheet supplied by Cut Plastics Ltd, Walsall, UK. The PU disc was made by an injection moulding process in which a polydimethylsiloxane (PDMS) mould was first fabricated around a non-coated glass disc supplied by PCS Instruments. Waterclear PU3660 part A and part B supplied by Alchemie Limited (Warwick, UK) were thoroughly mixed together and degassed before the mixture was poured into the PDMS mould. Several small batches were mixed separately at the same time, since mixing a too high volume of PU resulted in self heating (thus too fast curing) and increased degassing time. Even though initial full hard curing time at room temperature was less than $24 \mathrm{~h}$, it was found necessary to leave the PU in the mould for 4 days to avoid deformation of the disc during the demoulding process. Furthermore, once demoulded, discs were left on a flat PDMS surface for $24 \mathrm{~h}$ in order to ensure full strength of the edge thickness and another $24 \mathrm{~h}$ inverted to allow for the contact surface to fully strengthen. This process gives roughness similar to that of the original glass disc $(\mathrm{Ra}<2 \mathrm{~nm})$ and has also been used to manufacture polymer balls.

Table 1. Polymer discs studied

\begin{tabular}{|c|c|c|c|c|c|}
\hline & Material & Thickness & $\begin{array}{c}\text { Surface } \\
\text { Roughness, } \\
\text { Ra }\end{array}$ & $\begin{array}{c}\text { Elastic } \\
\text { modulus }\end{array}$ & $\begin{array}{c}\text { Poisson's } \\
\text { ratio }\end{array}$ \\
\hline PMMA & $\begin{array}{l}\text { Polymethyl- } \\
\text { methacrylate }\end{array}$ & $10 \mathrm{~mm}$ & $<4 \mathrm{~nm}$ & $3.3 \mathrm{GPa}$ & 0.39 \\
\hline PU & Polyurethane & $10 \mathrm{~mm}$ & $<4 \mathrm{~nm}$ & $1.85 \mathrm{GPa}$ & 0.48 \\
\hline
\end{tabular}


Both discs were coated by a $20-30 \mathrm{~nm}$ thick semi-reflective chromium coating. Disc coating was arranged by PCS Instruments and employed a magnetron sputtering technique with a low target power to avoid damaging the polymer disc. Such a very thin coating has negligible effect on the contact-scale elastic deformation. In order to prepare the discs for sputter coating, they were wiped with soft tissue using small quantities of isopropanol.

The elastic moduli listed in Table 1 were determined by measuring the contact diameter formed between a stationary, coated polymer disc and a $19 \mathrm{~mm}$ diameter steel ball at several loads and $40^{\circ} \mathrm{C}$. Figure 3 shows the resulting graphs in the form $a^{3}$ versus $W$ where $a$ is the contact radius and $W$ the applied load. According to Hertz theory the contact radius is related to load by;

$$
a^{3}=\frac{3 W R^{\prime}}{2 E^{\prime}}
$$

so the reduced elastic modulus, E' can be calculated from the gradients of the plots in Fig. 3 [37]. The disc's elastic moduli were then extracted from $E^{\prime}$ using the values of $E_{\text {steel }}=210$ GPa and $v_{\text {steel }}=0.3$ and the polymer disc material Poisson's ratio values shown in Table 1 , which were obtained from the literature. It should be noted that for the purposes of this paper the independent values of $E$ and $v$ for the polymers are immaterial since the value used for film thickness analysis is the reduced elastic modulus of the polymer-steel combination, $E^{\prime}$. The error limits for the obtained Young's moduli are governed by the error margins of the loading system. For loads below $5 \mathrm{~N}$ the error is estimated of up to $10 \%$, while for higher loads the error range was significantly less. Thus the Young's modulus determined for PU is estimated to have error margin of $\pm 5 \%$, while that of PMMA is estimated to be $\pm 2 \%$.

Film thickness tests were carried out over the range of conditions, $U=0.135 \mathrm{~m} / \mathrm{s}$ to $4 \mathrm{~m} / \mathrm{s}, W$ $=5,10$ and $15 \mathrm{~N}$, and slide roll ratio, $S R R=-1.5$ to 2 , where $S R R$ is defined as the ratio of sliding to mean rolling speed, $\left(u_{D}-U_{B}\right) / U$, where $u_{D}$ and $u_{B}$ are the surface speed of the disc and ball respectively and $U$ is the mean rolling speed, $\left(U_{B}+U_{D}\right) / 2$. All tests were carried out at $40^{\circ} \mathrm{C}$. For PMMA-steel, loads $5 \mathrm{~N}, 10 \mathrm{~N}$ and $15 \mathrm{~N}$ corresponded to mean Hertz pressures of 35,45 and $51 \mathrm{MPa}$ respectively while for PU-steel the corresponding mean pressures were 27, 34 and $39 \mathrm{MPa}$. The above test conditions meant that all tests operated in the isoviscous-elastic regime within the region shown as an elongated diamond in Fig. 1. 


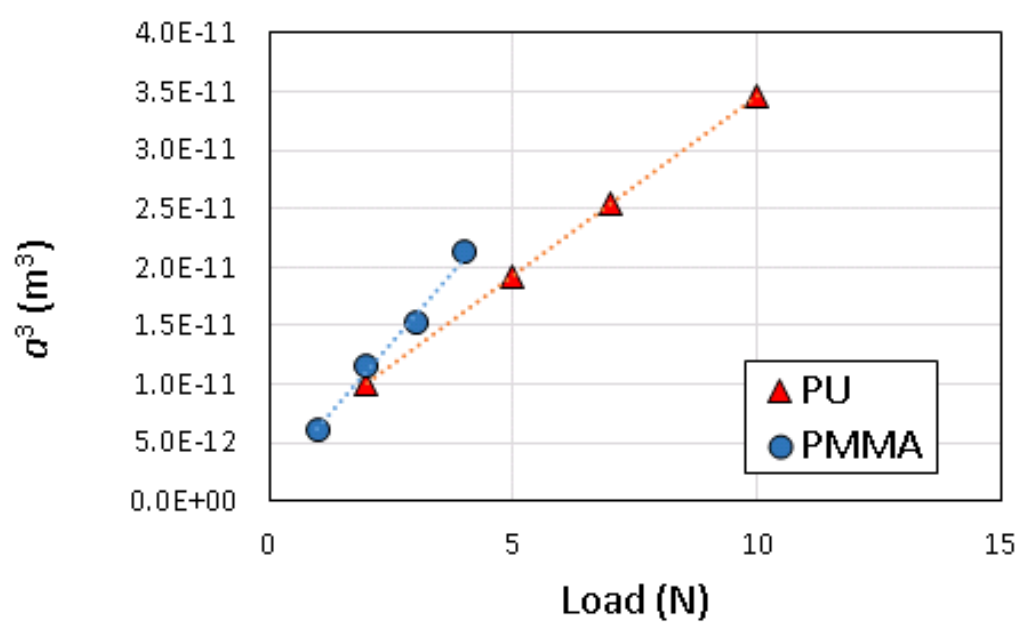

Figure 3. Plots of contact radius versus applied load used to determine E'

Normally the ball is part-immersed in lubricant. However for pure sliding with $S R R=2$ the ball does not rotate so that it is unable to draw lubricant from the reservoir into the contact. In this case the disc surface was copiously supplied with oil at the start of a test and the test time limited to avoid possible starvation. It was not possible to test the case of $S R R=-2$ with the disc stationary since the software system for image capture required triggering from the rotating disc.

Two additive-free base fluids were used in this study, both of gas-to-liquid origin and corresponding broadly to API Group III+. Their viscometric properties are listed in Table 2. Viscosities were measured using an Anton Paar SVM 3000 Stabinger viscometer. A nonpublished extensive study on this instrument implementing a series of base oils and cleaning methods confirms an error margin of below $\pm 0.5 \%$ when the instrument is run by an experienced operator. The effective pressure viscosity values, $\alpha$, listed in Table 2, which were used solely to plot the range of study in Fig. 1, were determined by comparing EHD film thickness measured by optical interferometry with the EHD film thickness formed by a reference oil of known $\alpha^{*}$ [17]. Refractive indices of the lubricants, required to convert optical to spatial film thickness, were measured using an Abbe refractometer.

Table 2. Viscosities of test fluids

\begin{tabular}{|c|c|c|c|c|c|c|}
\hline & $\begin{array}{c}\text { Viscosity } \\
40^{\circ} \mathrm{C} \\
\mathrm{CP}\end{array}$ & $\begin{array}{c}\text { Viscosity } \\
100^{\circ} \mathrm{C} \\
\mathrm{CP}\end{array}$ & $\begin{array}{c}\text { Density } \\
40^{\circ} \mathrm{C} \\
\mathrm{g} / \mathrm{cm}^{3}\end{array}$ & $\begin{array}{c}\text { Density } \\
100^{\circ} \mathrm{C} \\
\mathrm{g} / \mathrm{cm}^{3}\end{array}$ & $\begin{array}{c}\text { Effective } \\
\alpha \text {-value } \\
40^{\circ} \mathrm{C} \\
\mathrm{GPa}^{-1}\end{array}$ & $\begin{array}{c}\text { Effective } \\
\alpha \text {-value } \\
100^{\circ} \mathrm{C} \\
\mathrm{GPa}^{-1}\end{array}$ \\
\hline GTL4 & 14.77 & 3.08 & 0.80 & 0.76 & 14 & 12 \\
\hline GTL8 & 35.86 & 5.93 & 0.81 & 0.78 & 15 & 12 \\
\hline
\end{tabular}




\section{OPTICAL INTERFEROMETRY METHOD}

The light source was a white LED showing two marked peaks, one at around $460 \mathrm{~nm}$, the other at $560 \mathrm{~nm}$. The relative sharpness of the peaks gave rise to good fringe visibility in the three channels (red, green and blue) and this meant that films up to 1.5 microns thick could be measured, although the maximum film thickness reached in this study was only 1.2 microns.

In order to characterise the light source a static contact was initially produced between a chromium-coated glass disk and a steel ball and the contact flooded with lubricant. The resulting interference fringes were scanned radially and fringe intensities in the red, green and blue channels were plotted against the gap calculated using Hertz theory [37]. As described in Guegan et al. [38] the intensities were then normalised by the neighbouring minimum and maximum value of the intensity for each branch, so as to obtain values between -1 and 1 .

This process produces sinusoidal curves whose periods correspond to the average wavelength of the light source modulated by the response of the camera. The shifts of these curves gives the phase shift resulting from reflection from the chromium layer. Analysis of the fringes gave the properties of the light source and the optical system shown in Table 3.

Table 3. Wavelengths of RGB optical channels and phase shift of coated glass disc

\begin{tabular}{|c|c|c|c|}
\hline$\lambda_{\text {Red }}$ & $\lambda_{\text {Green }}$ & $\lambda_{\text {Blue }}$ & $\varphi$ \\
\hline $590 \mathrm{~nm}$ & $520 \mathrm{~nm}$ & $470 \mathrm{~nm}$ & 0.15 \\
\hline
\end{tabular}

According to theory, the period of the fringes against film thickness for a light source with wavelength $\lambda$, i.e. the difference in film thickness between two consecutive peaks or troughs is:

$$
T=\frac{\lambda}{2 n}
$$

where $n$ is the refractive index of the oil. In these tests, the refractive index was measured as 1.450 for the GTL4 and 1.455 for GTL8 at $40^{\circ} \mathrm{C}$. This difference was too small to have any significant impact on the periods, so the same mean value was used for both oils to give $T_{R}$ $=203 \mathrm{~nm}, T_{G}=179 \mathrm{~nm}, T_{B}=165 \mathrm{~nm}$ 
A similar procedure was then carried out in static contacts formed between the two polymer discs and the steel ball. Using the wavelengths calculated above, this resulted a non-zero film thickness in the contact area due to a different phase shift and from this a revised phase shift value could be determined. This was done for the three channel profiles independently, but the phase shifts obtained from all were identical, at a value of 0.10 for both polymers. This approach avoided making the assumption that the static polymer-steel contacts were Hertzian, although in practice their profiles were found to be very close to this.

One of the problems in optical interferometry, especially when studying thick lubricant films, is to determine the correct interference order. This can be done by counting the order change while gradually increasing the entrainment speed and thus the film thickness from zero. In the current study this was combined with a method for directly determining order, as described below.

After each polymer-steel test, the interference images (interferograms) were post-processed individually. An image contains three colour planes, one for each channel. As shown below in Fig. 4, a rectangular strip was selected that traversed the contact and for each channel the intensities of the pixels across the thickness of this strip were averaged to reduce noise. Typically 15 pixels were averaged, few enough to ensure the thickness was essentially constant in the direction averaged. This gave $\mathrm{R} \mathrm{G}$ and $\mathrm{B}$ intensity profiles across the contact as shown in Fig. 5(a). As explained above and shown in Figure 5(b) the three intensity curves were then normalised between -1 and 1 .

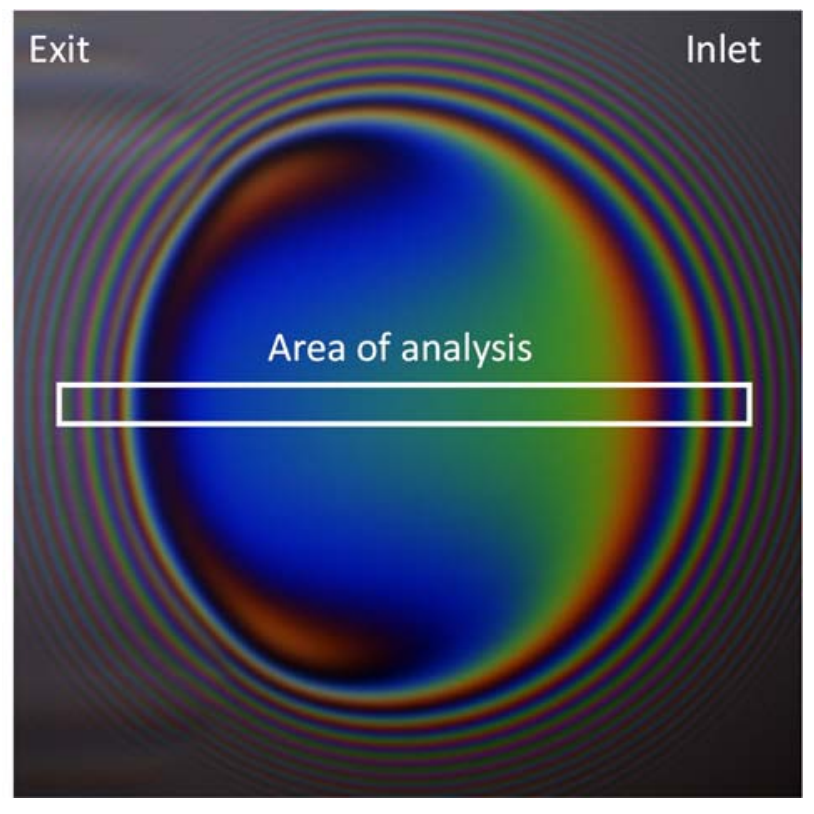

Figure 4: Interferogram showing the rectangular region where the film profile is calculated (PMMA, GTL8, $W=5 \mathrm{~N}, \mathrm{U}=1.6 \mathrm{~m} / \mathrm{s}, S R R=0$ ) 

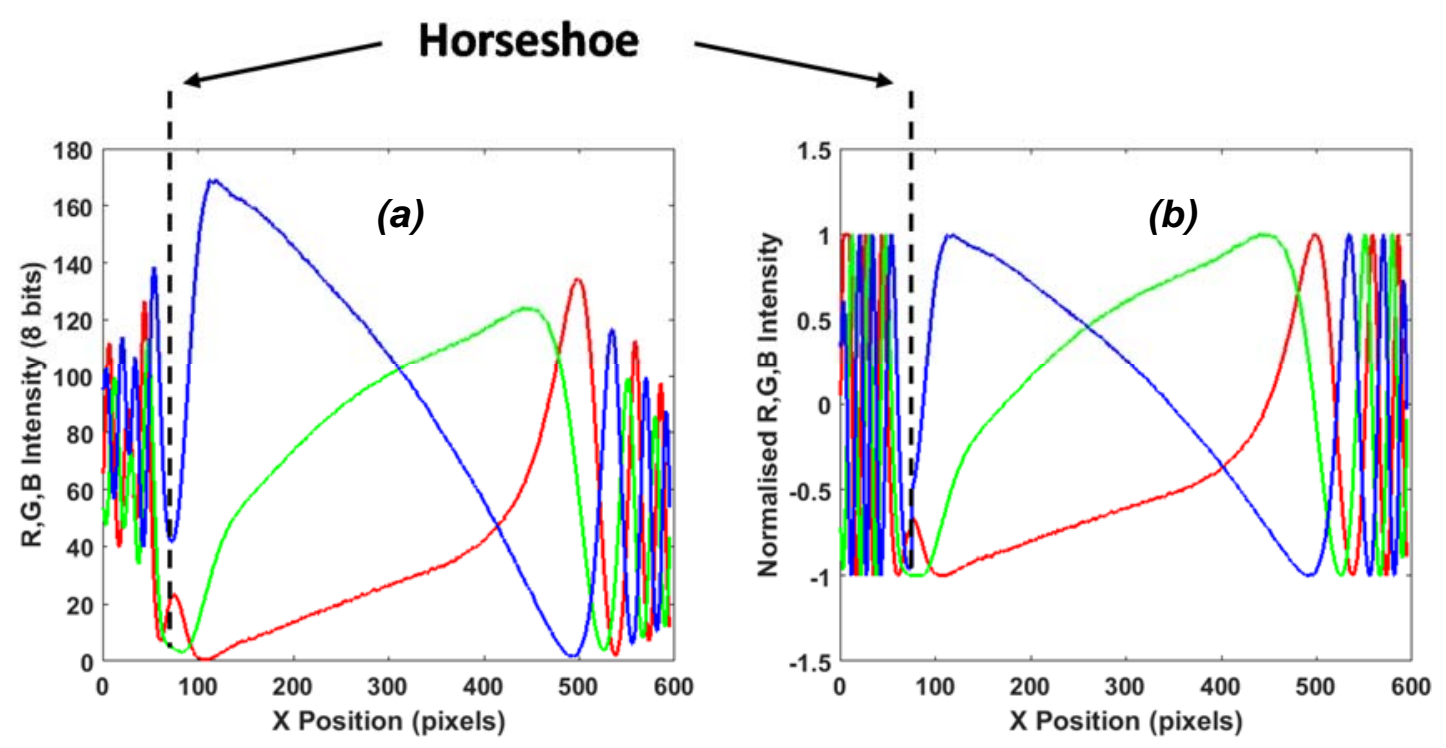

Figure 5(a) Measured intensity along the contact and 5(b) normalised intensity; the position of the horseshoe minimum is also shown

As noted above, the difference in film thickness between two peaks or troughs depends on the wavelength of the light source. Assuming the film thickness evolves monotonically (positively or negatively), the fringes can then be counted and the difference in film thickness between two points calculated. For the points that do not lie at a minimum or maximum of intensity the film thickness was calculated based on the thickness varying with the arcosine of the normalised intensity. A more detailed mathematical treatment of this process can be found in Guegan et al. [38].

For each image, the minimum of the horseshoe (at the rear or the side of the contact depending on the direction of the strip being analysed) was identified manually, its position usually being obvious as it corresponds to a cusp on the curve. This enabled a profile to be separated into two parts in which the film evolves monotonically. In Fig. 5(b), from position $x$ $=0$ to the minimum of the horseshoe the film decreases, after which it increases. Using this assumption, film thickness profiles can be calculated independently for each channel based on assuming the order of interference at the horseshoe minimum. However in Fig. 6 it can be seen that if an incorrect order is picked the different profiles do not match. Thus the correct order can be determined as that which gives a good match for the thicknesses calculated from the three colour channels, as shown in Fig. 7(a). The final profile was then taken to be the average of these three, as shown in Fig. 7(b). 


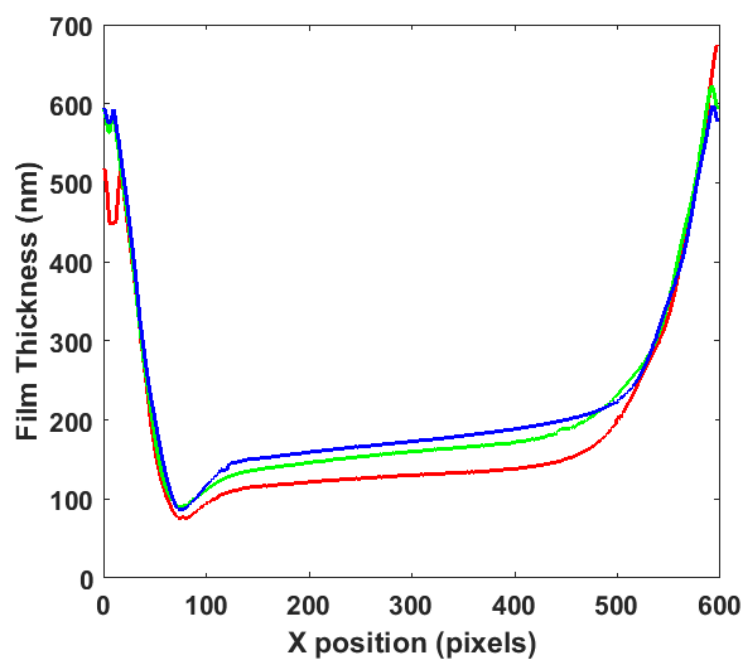

Figure 6 Film thickness profiles obtained from Fig. 5b using an arbitrary interference order
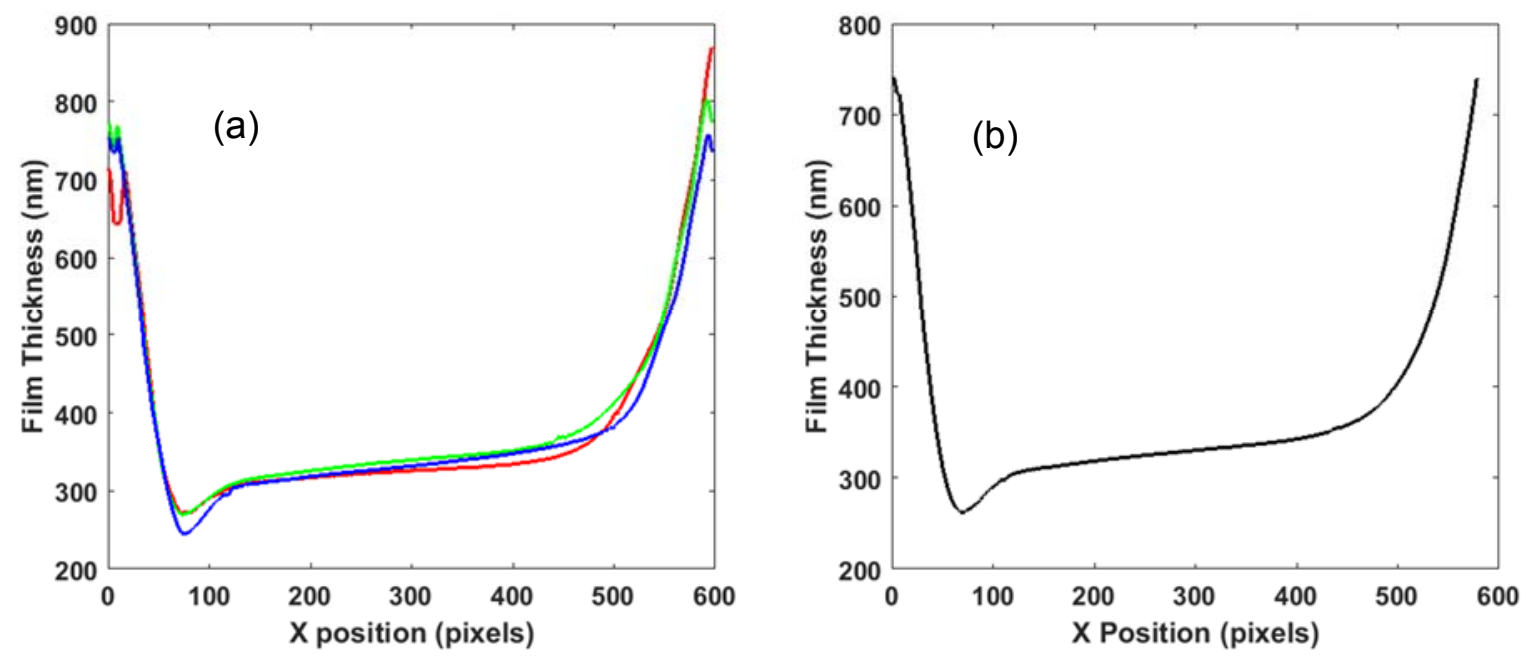

Figure 7(a) Matching profiles for the three colour channels, 7(b) Average profile

From these profiles it was quite straightforward to determine the minimum film thickness at the exit of the contact (and for transverse profiles the minimum at the side lobes). Determination of the central film thickness was more problematic due to difficulty in identifying the contact centre precisely and also because the film thickness varied considerably across the contact at high entrainment speeds. The centre position was estimated by aligning a square over the image so the centres of the sides of the square formed tangents to matching fringes on either side of the contact. The contact centre was then taken to be the centre of this square and the central film thickness was calculated as the average film thickness over an area corresponding to one tenth of the contact size around this central point. 


\section{RESULTS}

Figure 8 shows a series of images for a PMMA disc on steel ball lubricated by GTL8 at SRR $=0$ and a load of $10 \mathrm{~N}$. In all cases the inlet is at the bottom of the image and the exit at the top. It can be seen that the use of a chromium semi-reflective layer gives high quality interference images, similar to those obtained using a steel-on-glass disc contact as described by Foord et al. [16, 39]. All images show the characteristic horseshoe at the rear and sides of the contact and in all of these images the absolute minimum film thickness occurs in the side-lobes.

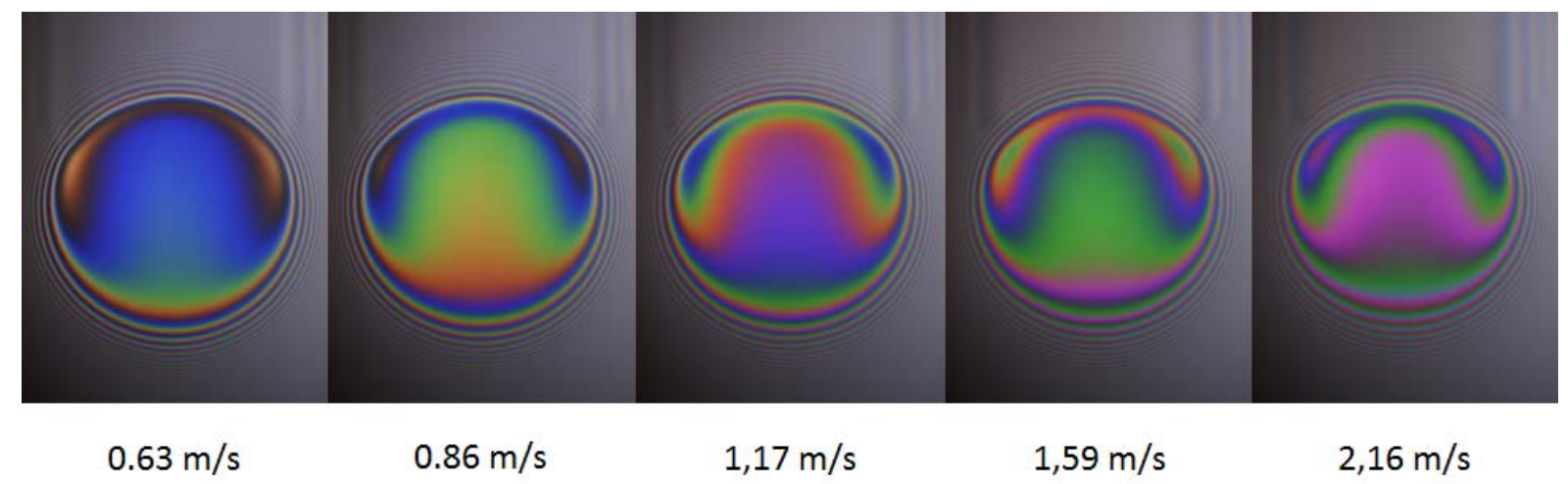

Fig. 8 Interferograms of the contact of PMMA disc/steel ball lubricated with GTL8 at 10N

$$
\text { load and } S R R=0
$$

Analysis of the above images together with those at other entrainment speeds gives the profiles across the centreline from inlet to exit shown in Fig. 9. The inlet is on the right of these profiles. At low speeds the central region is almost flat, similar to piezoviscous-elastic contacts, but as the speed increases a wedge-shaped film is developed. It should be noted that the thickness values in the exit beyond the minimum are not reliable because of film cavitation. 


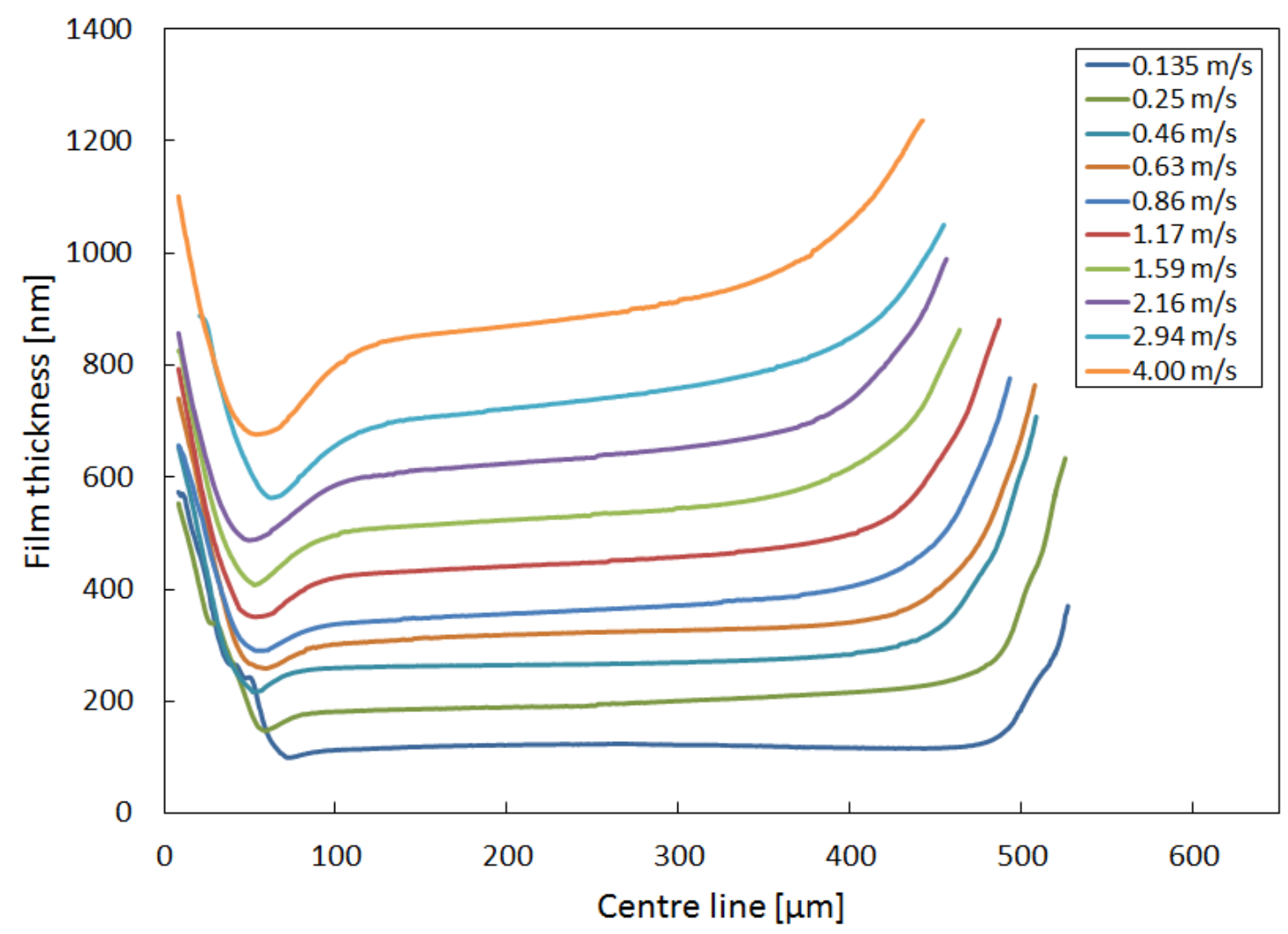

Fig. 9. Influence of entrainment speed on centreline film thickness profiles for PMMA disc and GTL8 at $10 \mathrm{~N}$ load and $S R R=0$ (inlet on right)

Figure 10 shows plots of $\log \left(h_{c}\right)$ versus $\log (U)$ for all polymer and viscosity combinations at $10 \mathrm{~N}$ load and $S R R=0$. All give straight line plots with gradients in the range 0.51 to 0.56 . Minimum film thickness values in the exit (along the centreline) also gave straight line plots of similar gradient. 


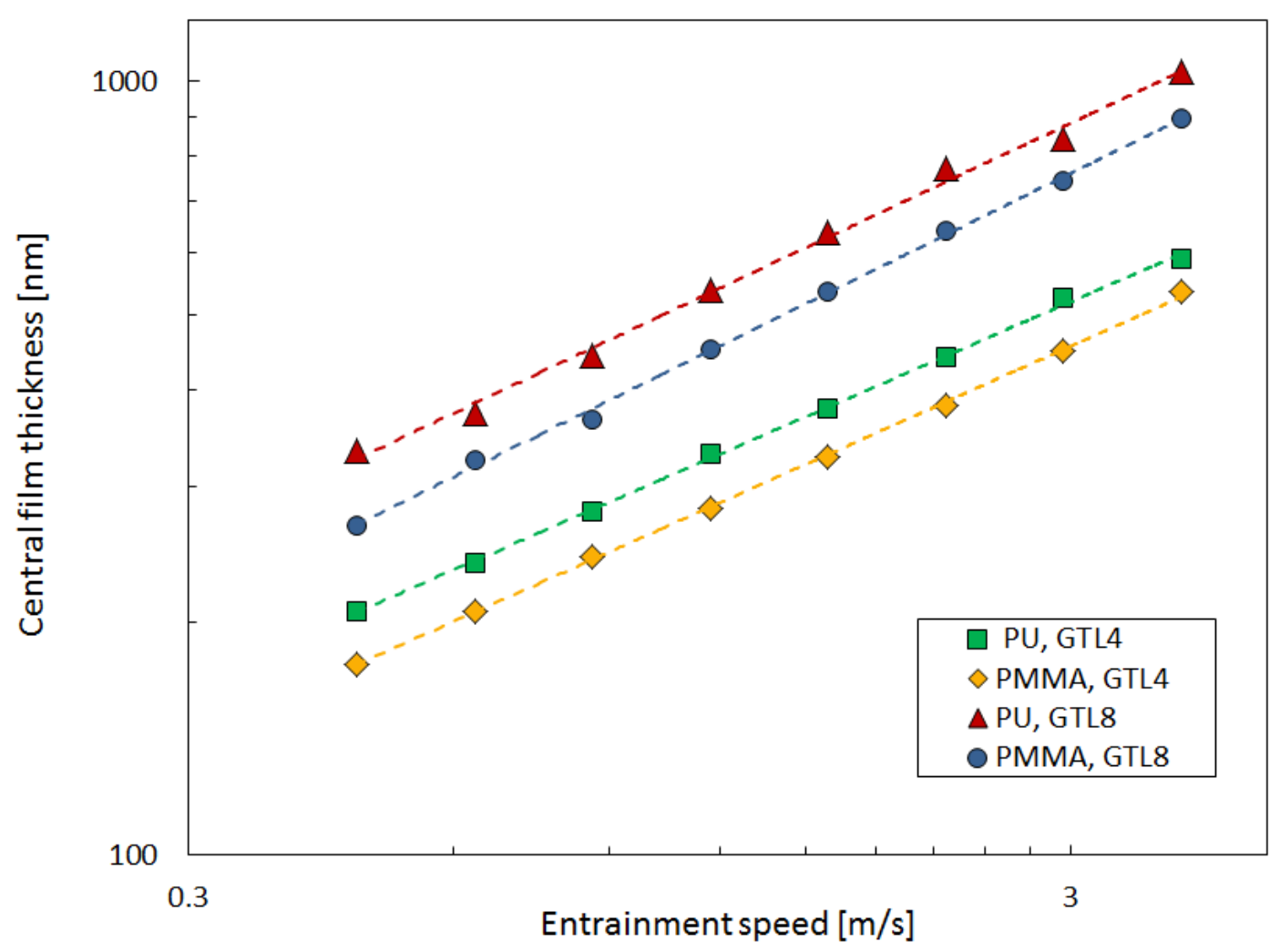

Fig. 10. Log(central film thickness) versus log(entrainment speed) for all four polymer/base oil combinations at $10 \mathrm{~N}$ load and $S R R=0$

To confirm the validity of the RGB film thickness method used, central film thickness measurements were also made using the ultrathin film interferometric approach normally employed with the PCS Instruments optical test apparatus. This is based on spectrometric analysis of the emitted light to determine the wavelength of maximum constructive interference and thus the film thickness. This method's error limits are stated to be $\pm 5 \mathrm{~nm}$ [40]. Figure 11 compares the measurements obtained using the two methods and shows very close agreement between them suggesting that the error limits using the RGB approach is similar up to a film thickness of $200 \mathrm{~nm}$. Above this the error limit $\pm 4 \%$. 


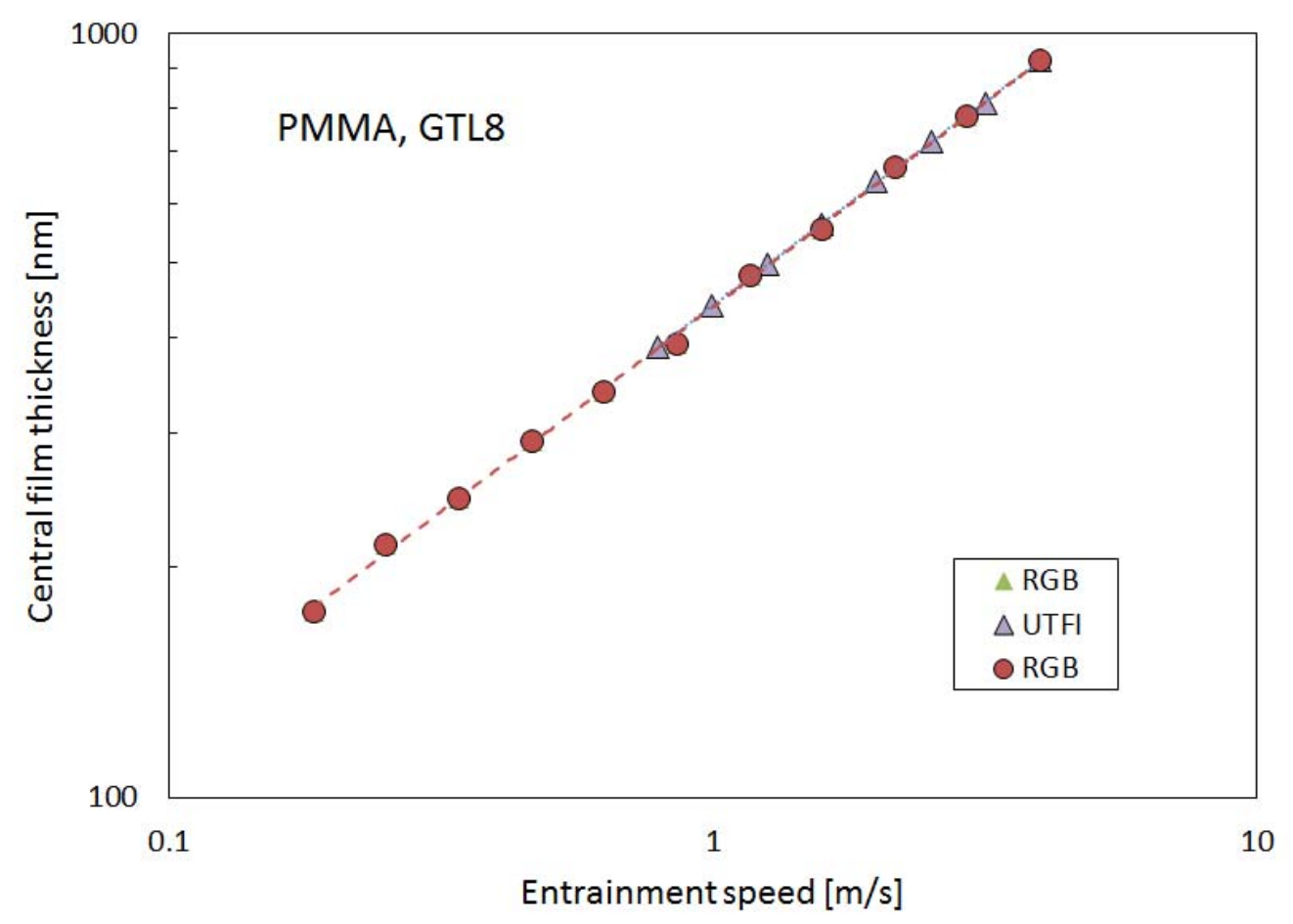

Fig. 11. Comparison of central film thickness measured using RGB and the UTFI methods

Figure 12 shows interferograms for PMMA with GTL8 at a fixed entrainment speed of 1.59 $\mathrm{m} / \mathrm{s}$ and three different applied loads. The size of the contact increases rapidly with applied load but the central and exit minimum film thickness change relatively little. Profiles across the centreline from these images are shown in Fig. 13, while Fig. 14 which shows central film thickness plotted against entrainment speed for PMMA with GTL8 at the three loads.

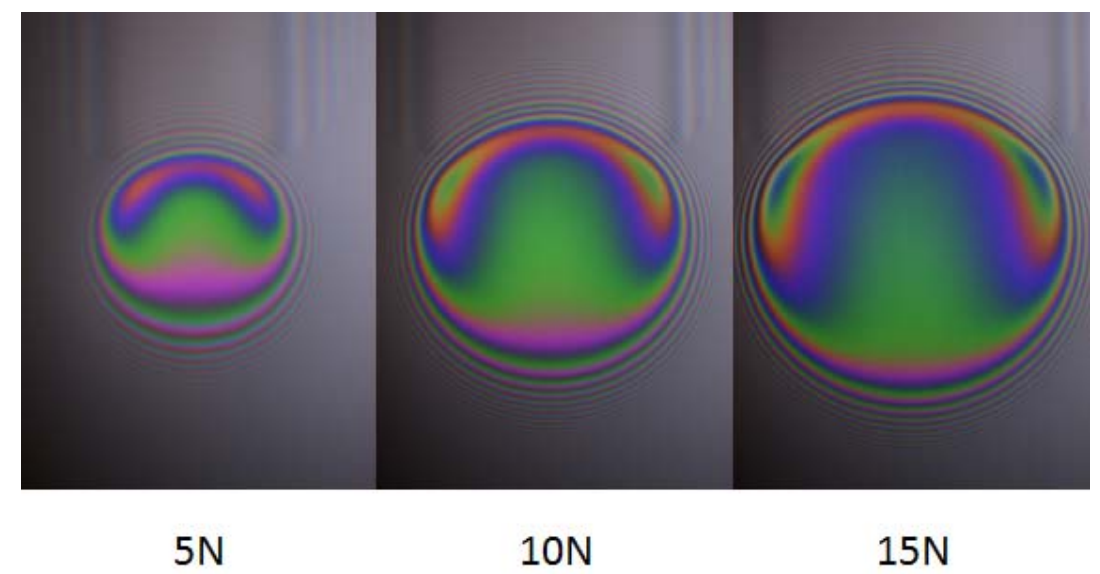

Fig. 12 Interferograms of the contact of PMMA disc/steel ball lubricated with GTL8 at 1.59 $\mathrm{m} / \mathrm{s}$ and three different loads. $S R R=0$ 


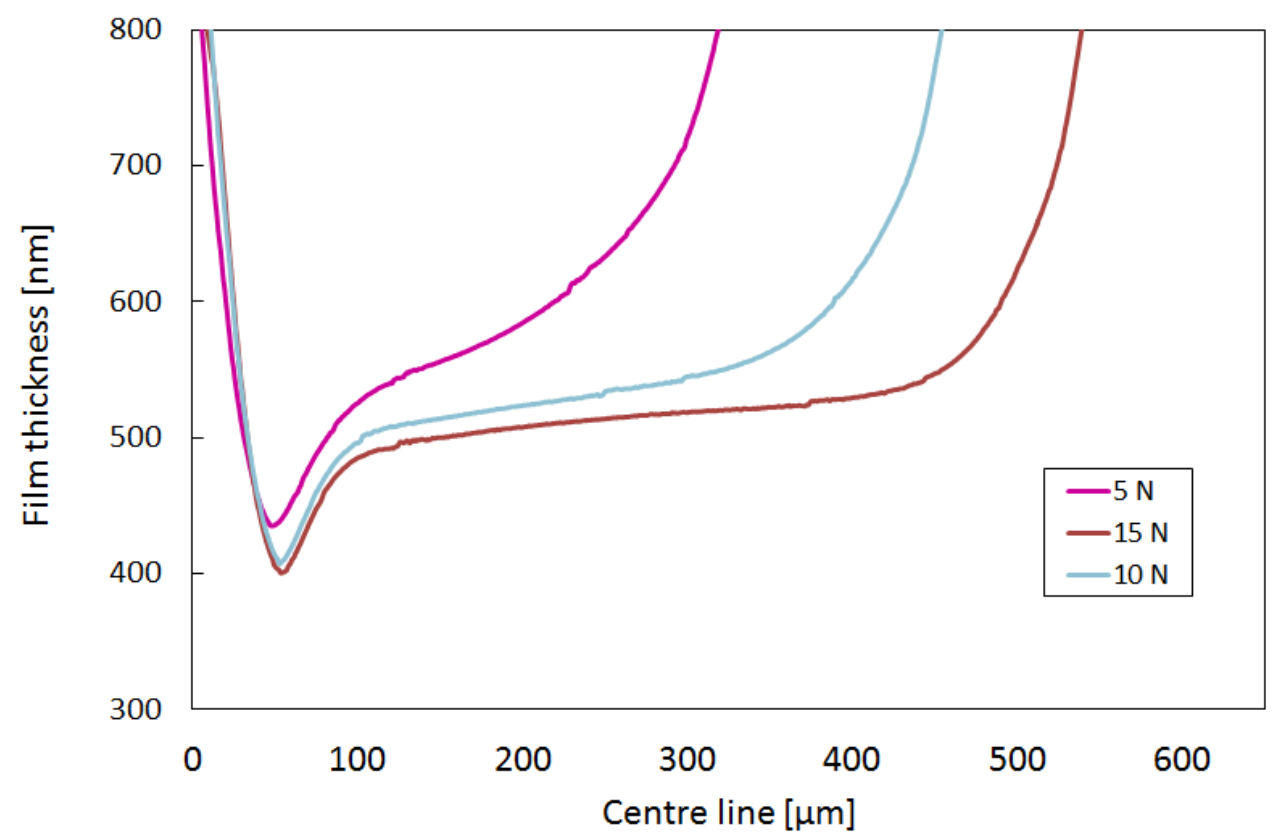

Fig. 13 Influence of load on centreline film thickness profiles for PMMA disc and GTL8 at entrainment speed $1.59 \mathrm{~m} / \mathrm{s}$ and $S R R=0$ (inlet on right).

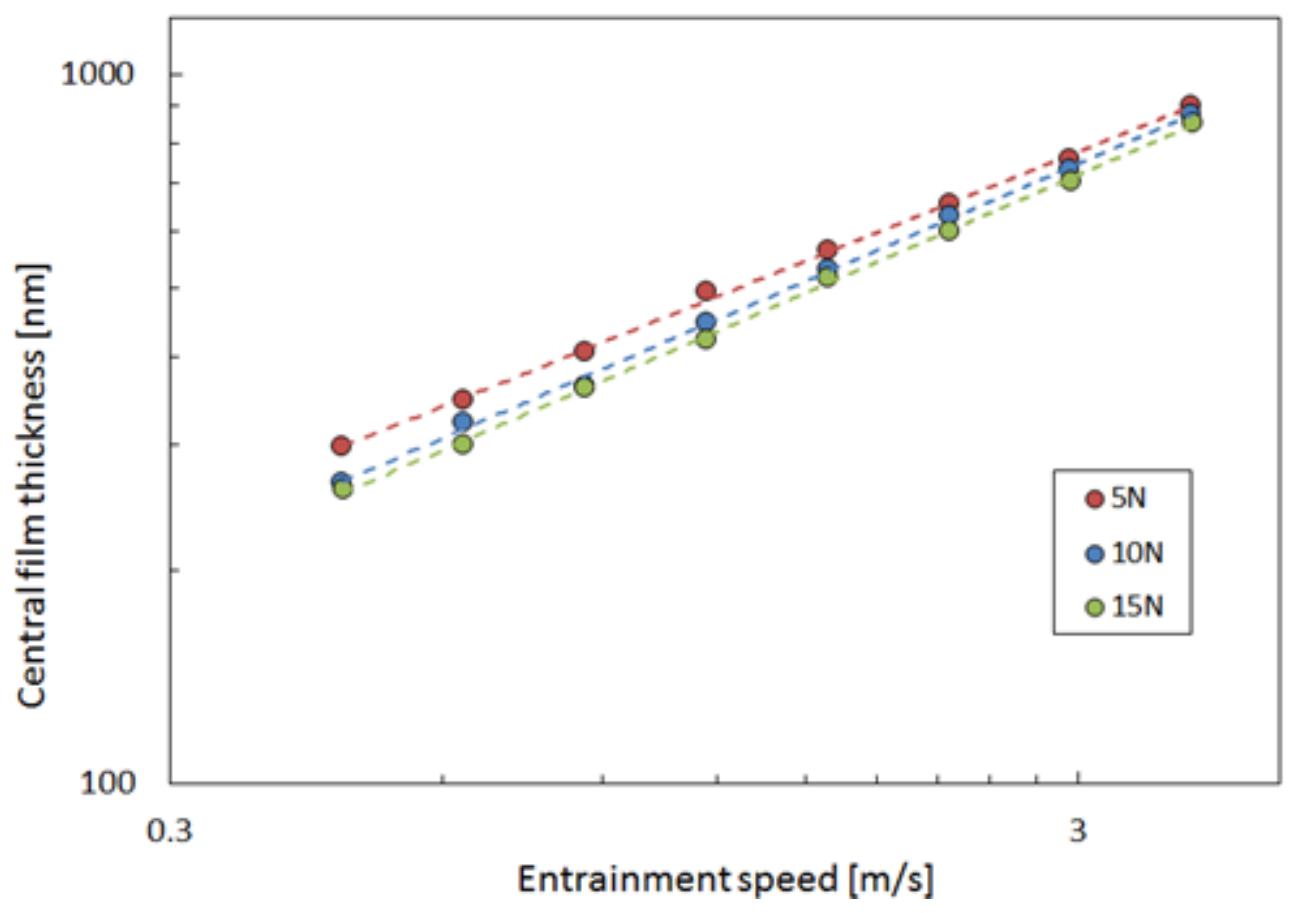

Fig. 14. Influence of applied load on log(central film thickness) versus log(entrainment speed) for PMMA and GTL8 at $S R R=0$. 
All of the above results were from nominally pure rolling conditions $(S R R=0)$. Figure 15 shows the influence of slide-roll ratio on central film thickness for PMMA at various entrainment speeds. In general, fluid entrainment and thus film thickness should depend only on entrainment speed and not on sliding speed and this is shown in Fig. 15 over most of the $S R R$ range. The exception is at high SRRs, when shear heating can result in heating of the surfaces in the contact inlet leading to a reduced lubricant viscosity in the inlet and thus to a thinner film. For piezoviscous-elastic contacts this starts to be significant at $S R R>50 \%$ [18] but for the isoviscous-elastic contacts in this study, film thickness remains almost constant over most of the range of SRR. This is because much less heat is generated in these low pressure contacts, where there is negligible piezoviscous effect and so lower friction than in high pressure EHD contacts. A significant drop in film thickness is, however, seen at $S R R=200 \%$. At this SRR the steel ball is stationary, so heat entering the ball surface within the contact is not convected towards the contact exit by rotation of the ball. This may result in an increase in ball surface temperature in the inlet.

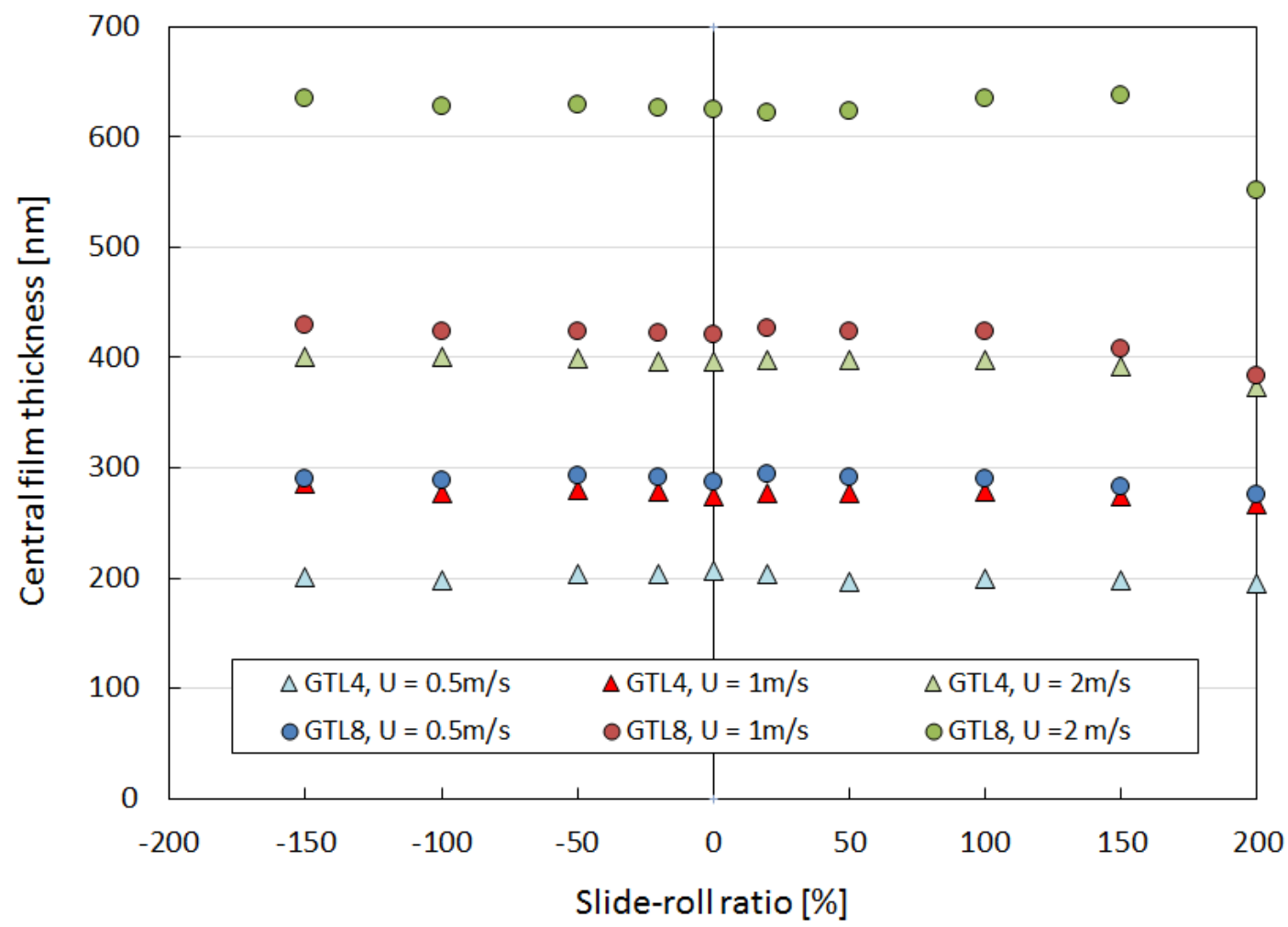

Fig. 15. Influence of slide-roll ratio on central film thickness for PMMA tests at $W=10 \mathrm{~N}$. 


\section{DISCUSSION}

Classical optical interferometry is traditionally applied to measure film thickness in piezoviscous-elastic EHL contacts. This work shows that by applying semi-reflective chromium coatings to the underside of the transparent polymer discs it can be equally well used to measure film thicknesses in the isoviscous-elastic contacts formed between polymer discs and steel balls using a commercial optical interferometry test apparatus. These coatings are quite robust and survive rolling-sliding and even pure sliding conditions so long as full film lubrication conditions are maintained. Films can be measured and mapped up to thicknesses in excess of one micron. A novel method of determining the order of the interference fringes has been developed based on matching calculations from the red, green and blue channels.

In this study it was found that both the central and minimum film thickness varied with entrainment speed to a power between 0.52 and 0.56 . This is less than predicted by previous theoretical studies which, as indicated in Equs. (5), (6), (10) and (12) suggest a power of 0.6 to 0.66 . This is illustrated in Fig. 16 where it can be seen that Dowson \& Hamrock [11], Esfahanian \& Hamrock [6] and Hooke [12] all predict thinner films at low speed than measured in this study.

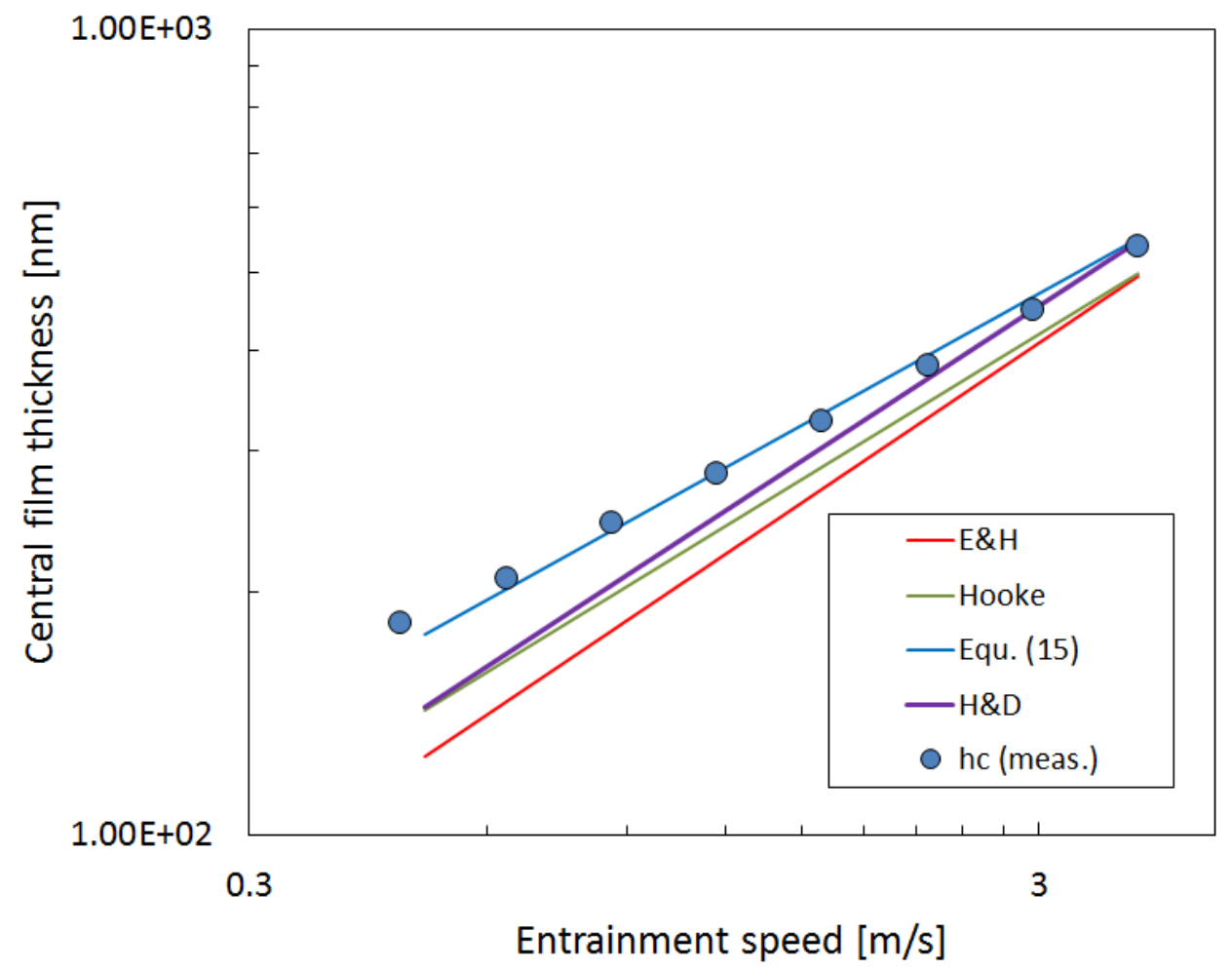

Fig. 16. Comparison of experimental results with measured central film thickness; PMMA, GTL4, SRR = 0 
Figure 17 shows that all combinations of load, lubricant viscosity and elastic modulus give essentially the same central film thickness versus entrainment speed response. The solid lines are predictions using Equ. (15).

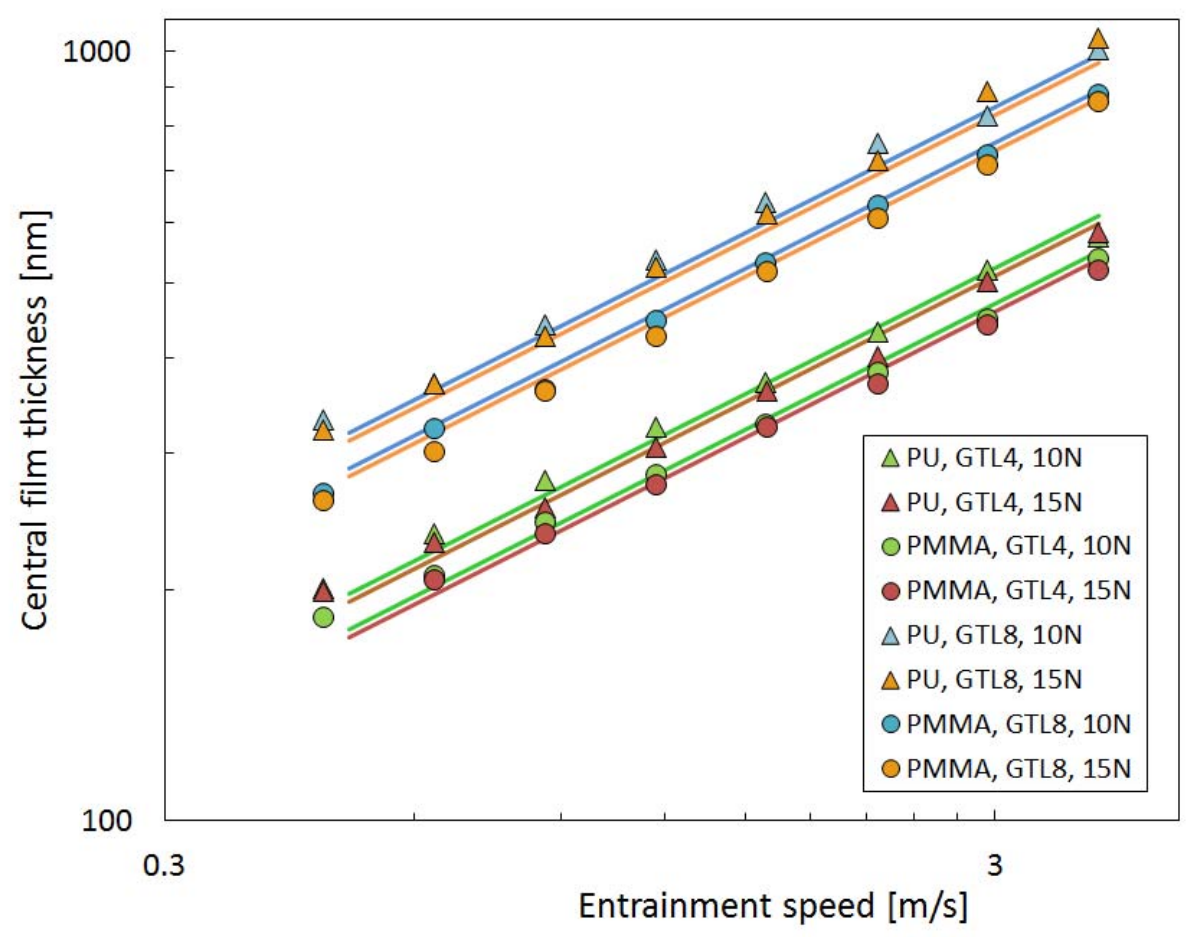

Fig. 17. Central film thickness versus entrainment speed for various load, viscosity and elastic modulus combinations

By combining all of the central film thickness versus entrainment speed plots, the best fit was found to occur with a speed exponent of 0.55, i.e. $h_{c}$ a $U^{0.55}$. Based on the definition of the elasticity parameter $g_{E}$ given earlier in this paper this implies a $g_{E}$ exponent of 0.725 and a load exponent of -0.067 . As shown in Fig. 18, using these exponents it was found that the best fit to all of the measured central film thickness data was given by

$\frac{h_{c}}{R_{x}{ }^{\prime}}\left(\frac{\bar{W}}{\bar{U}}\right)^{2}=2.7 g_{E}^{0.725}$

Figure 19 shows that a very similar relations exists for $h_{0}$ (exit) except that the constant is now 2.1, i.e.

$\frac{h_{o(\text { exit })}}{R_{x}{ }^{\prime}}\left(\frac{\bar{W}}{\bar{U}}\right)^{2}=2.1 g_{E}^{0.725}$

The $g_{E}$ exponents in these equations are somewhat greater than those given in Equs. (3) to (9), which were determined from regression fits of computed film thicknesses. 


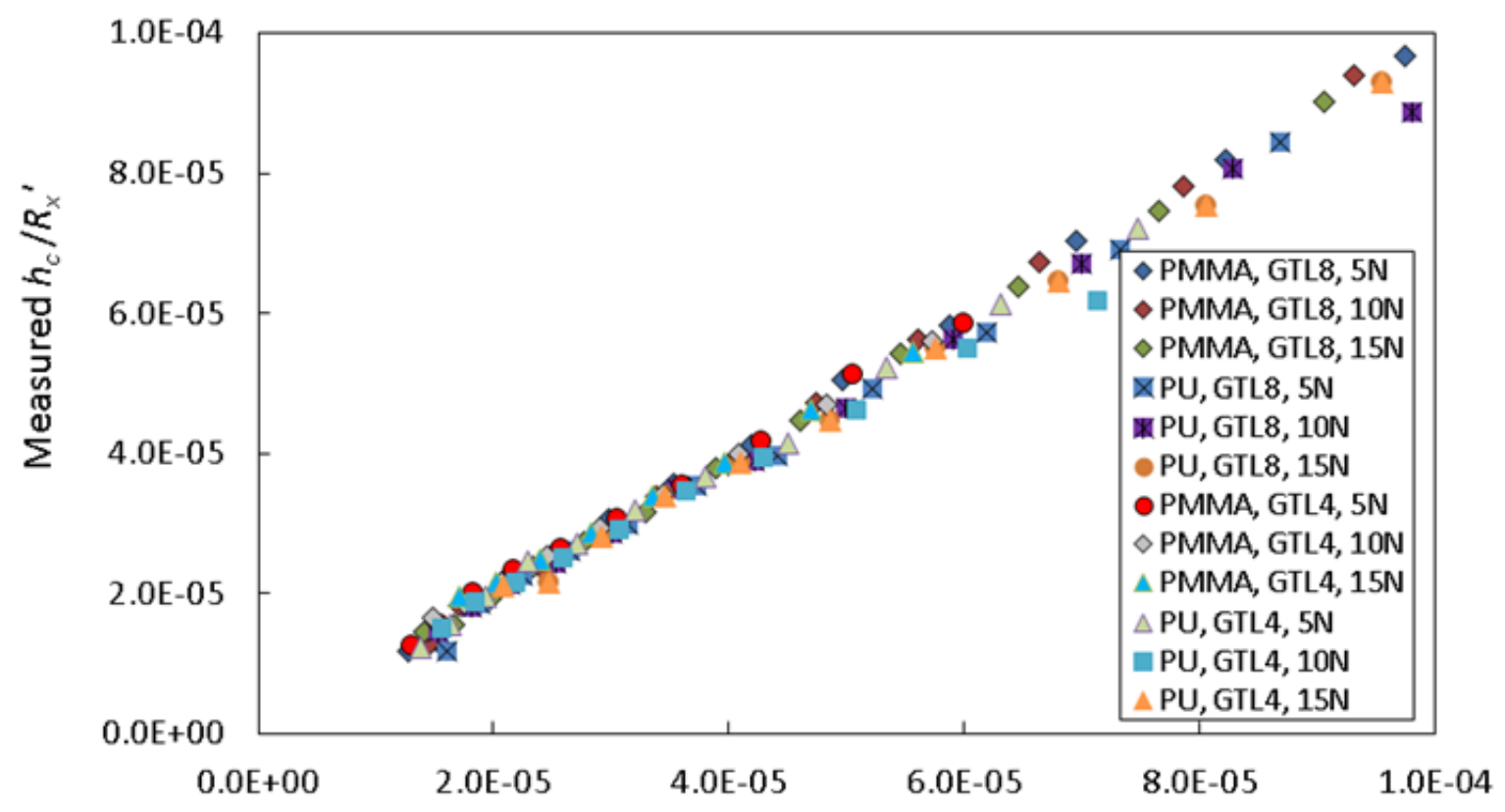

$2.7^{*}(\bar{U} / \bar{W})^{2} g_{\varepsilon}^{0.725}$

Fig. 18. Plot showing that all measured data fits equation $H_{C}=2.7 g^{0.725}$

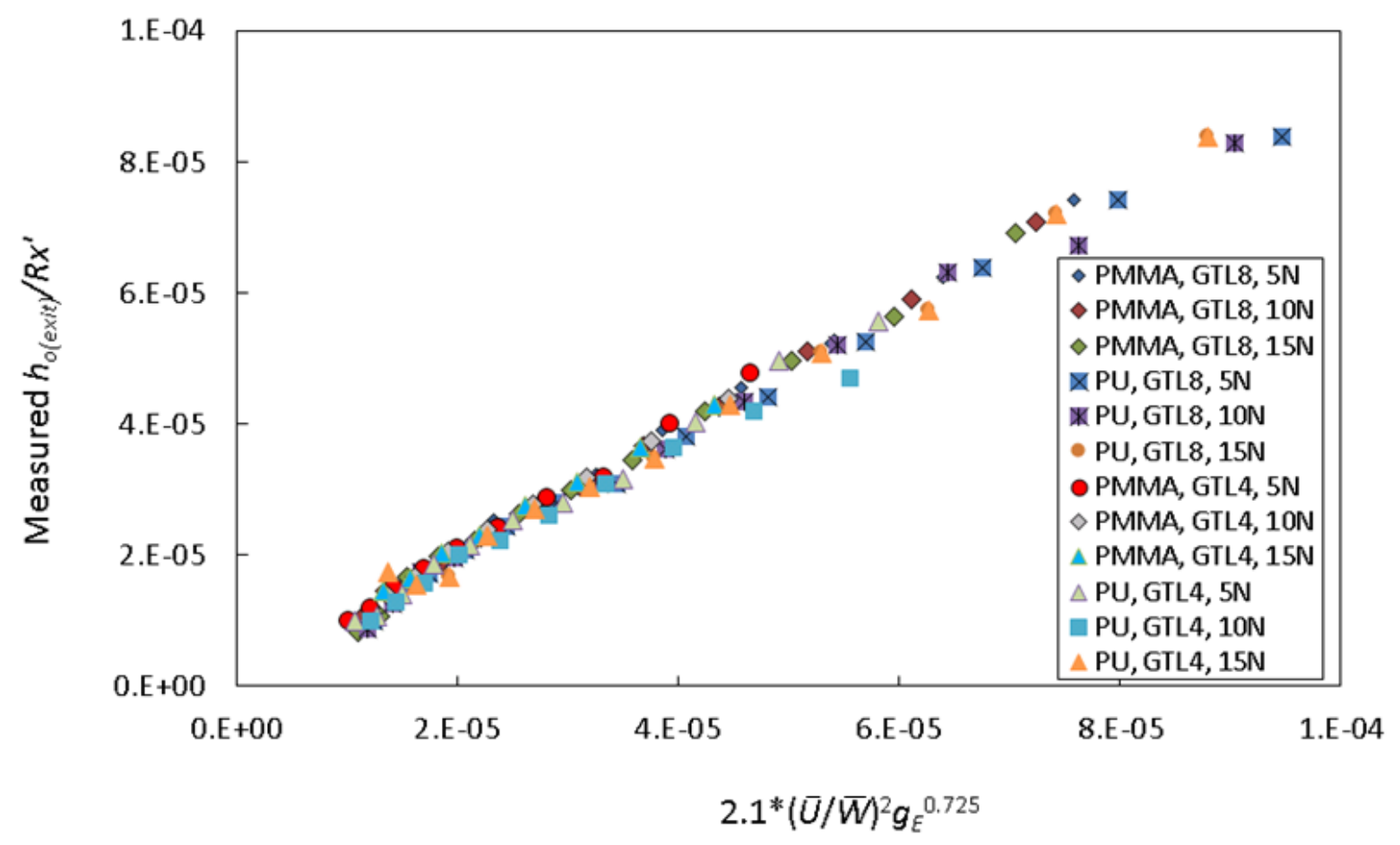

Fig. 19. Plot showing that all measured data fits equation $H_{O}(e x i t)=2.1 g_{E}^{0.725}$

Hooke has suggested that the absolute minimum film thickness moves from the side lobes to the exit of the contact as the entrainment speed increases or the load decreases [12]. For most of the conditions tested in this study the minimum was at the side lobes but for tests at 
the lowest load a transition was observed with increasing entrainment speed. This is shown in Fig. 20 where it can be seen that the minimum is at the sides of the contact at low speeds but the moves to the exit as the speed is raised. A similar transition can also be seen in Fig. 12 as the load is decreased.

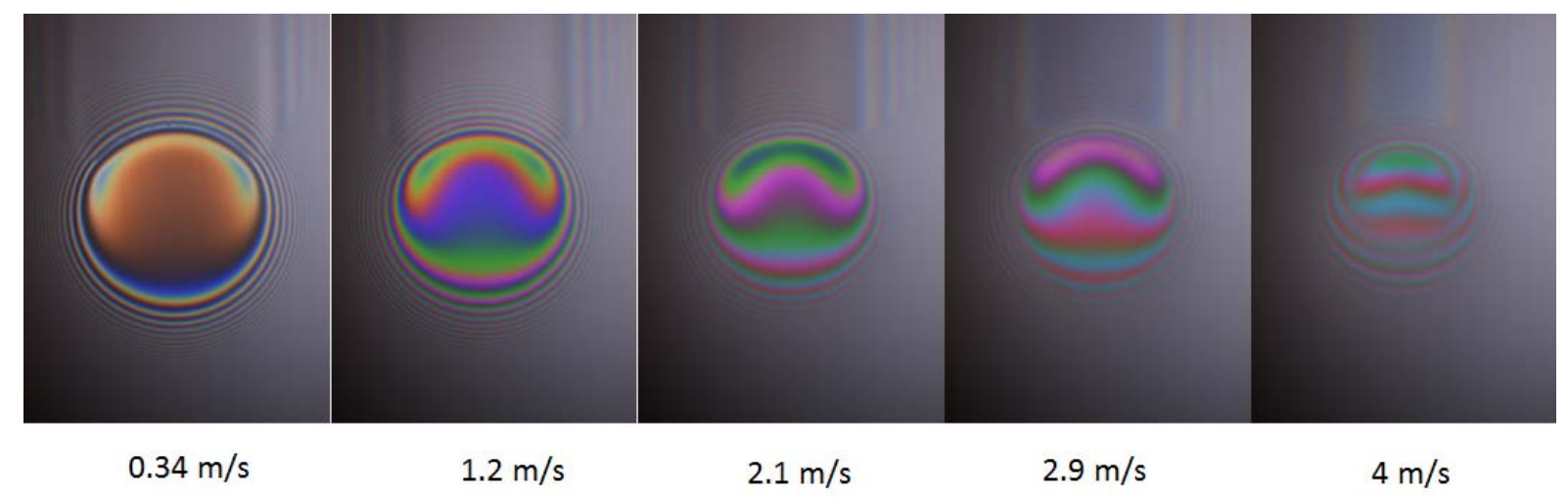

Fig. 20. Change in minimum film thickness position with entrainment speed, PMMA, GTL8, $\mathrm{W}=5 \mathrm{~N}, S R R=0$.

The minimum film thicknesses at the exit and side lobes from Fig. 20 are plotted against entrainment speed in Fig. 21 for PMMA, GTL8 and $5 \mathrm{~N}$ load. The transition of the absolute minimum from the side lobes to the rear of the contact occurs at $U=3 \mathrm{~m} / \mathrm{s}$ and $h_{\min }=595$ $\mathrm{nm}$. This does not agree with the location of the transition proposed by Hooke, which he suggested should occur at $g_{E}=2.6 \times 10^{6}$. Based on these measured results it should occur when $g_{E}$ is of order $10^{4}$, which would just intercept the tested region in Fig. 1.

The side lobe minimum film thickness data obtained in this study was fitted to $g_{E}$. This gave a fit of similar quality to those in Figs. 18 and 19 and the fitted equation was;

$\frac{h_{o(\text { side })}}{R_{x}{ }^{\prime}}\left(\frac{\bar{W}}{\bar{U}}\right)^{2}=2.9 g_{E}^{0.69}$ 


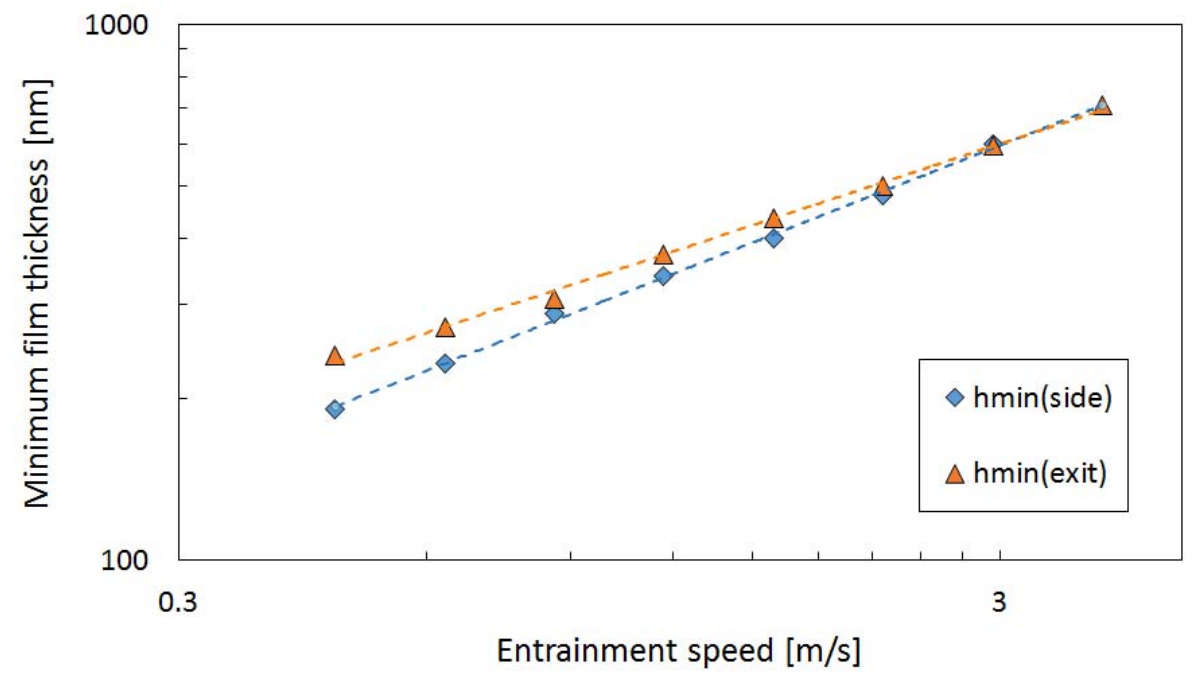

Fig. 21. Variation of exit and side lobe minimum film thickness with entrainment speed for PMMA, GTL8, $5 \mathrm{~N}$ and $S R R=0$

It is of interest to compare the finding of the current study with previous work on soft EHL film thickness, although unfortunately there is very little of the latter. Myant et al. used oblique angle interferometry to measure film thickness in a pure sliding, uncoated PDMS on glass contact [32]. This showed the formation of similar film shapes to those in the current study, with a wedged film at high speeds and a much flatter film at low speeds. However, Myant et al. measured film thicknesses less than half those predicted by Dowson and Hamrock and of our experimental measurements as summarised in Equ. (15) above. The origins of this discrepancy are not clear. Dowson and Hamrock's equation was derived from soft EHL solutions over the range of $5 \times 10^{-9} \leq \bar{U} \leq 5 \times 10^{-8}$ and $2 \times 10^{-4} \leq \bar{W} \leq 2 \times 10^{-3}$ [41]. Myant et al.'s experiments were under the conditions of order $\bar{U}=10^{-8}$ and $\bar{W}=2 \times$ $10^{-4}$ while in this paper, due to the higher elastic modulus polymer employed, mid-range conditions were $\bar{U}=2 \times 10^{-9}$ and $\bar{W}=5 \times 10^{-5}$. The discrepancy is thus not likely to originate from the use of different ranges of test conditions.

\section{CONCLUSIONS}

This study has shown for the first time that robust, chromium, semi-reflective coatings can be applied to transparent PMMA and polyurethane discs to make possible conventional optical interferometry in soft EHL conditions. High quality interferograms, comparable to those obtained from coated glass discs, are obtained and these enable detailed maps of lubricant film thickness to be calculated. A novel method of determining interference order has been developed to allow profiles of film thickness up to $1.5 \mu \mathrm{m}$ thick to be obtained from rolling 
and rolling-sliding and sliding contacts without the need to count fringe order while increasing progressively entrainment speed.

Measured film thicknesses have been compared with existing soft EHL film thickness equations obtained using computer modelling and revised central and exit minimum film thickness equations are proposed as follows;

$$
\begin{aligned}
& \frac{h_{c}}{R_{x}{ }^{\prime}}\left(\frac{\bar{W}}{\bar{U}}\right)^{2}=2.7 g_{E}^{0.725} \\
& \frac{h_{o(\text { exit })}}{R_{x}{ }^{\prime}}\left(\frac{\bar{W}}{\bar{U}}\right)^{2}=2.1 g_{E}^{0.725} \\
& \frac{h_{o(\text { side })}}{R_{x}{ }^{\prime}}\left(\frac{\bar{W}}{\bar{U}}\right)^{2}=2.9 g_{E}^{0.69}
\end{aligned}
$$

The transition of absolute minimum film thickness from the exit of the contact to the side lobes, as predicted theoretically, has been observed experimentally for the first time. However this transition occurs at lower values of the elasticity parameter $g_{E}$ than suggested by previous modelling work

It has been shown that in soft EHL conditions, film thickness does not vary significantly with slide-roll ratio until pure sliding conditions are reached, when film thickness is reduced due to inlet heating.

These film thickness measurements have direct applicability to our understanding of the performance and design of lubricated gears and bearings manufactured from polymeric materials. However it should also be noted that the ability to accurately map film thickness in polymer-based, lubricated contact provides significant new opportunities in lubrication research; for example to study lubricant shear thinning in the low pressure, high shear rate conditions present in soft EHL contacts and to explore the impact of surface texture in such contact conditions. In the configuration used in this study it was essential that the coated polymer discs be transparent, since they formed part of the optical path. However in principle it should be possible to use a polymer ball coated with a thicker and thus fully reflective chromium layer and use this against a coated glass disc, thereby enabling opaque polymers to be studied. 


\section{ACKNOWLEDGEMENTS}

Johan Guegan and Nigel Marx are supported by the Shell University Technology Centre for Fuels and Lubricants at Imperial College London.

\section{REFERENCES}

[1] Lawrence, C.C., Stolarski, T.A. Rolling contact wear of polymers: a preliminary study. Wear. 1989;132:183-191.

[2] Walton, D., Shi, Y.W. Comparison of ratings for plastic gears. Proc. I. Mech. Eng. 1989;C203:31-38.

[3] Dearn, K.D., Hoskins, T.J., Andrei, L., Walton, D. Lubrication regimes in highperformance polymer spur gears. Adv. in Tribology. 2013;Article ID 987251.

[4] Johnson, K.L. Regimes of elastohydrodynamic lubrication. J. of Mech. Eng. Sci. 1970;12:9-16.

[5] Hamrock, B.J., Dowson, D. Minimum film thickness in elliptical contacts for different regimes of fluid film lubrication. Proc 5th Leeds-Lyon Symp. on Tribology, Elastohydrodynamics and Related Topics, MEP, Bury St. Edmunds, Suffolk.1979;22-27.

[6] Esfahanian M., Hamrock BJ.: Fluid-film lubrication regimes revisited. Trib.Trans. 1991;34:628-32.

[7] Hamrock, B.J.: Fundamentals of Fluid Film Lubrication, McGraw Hill Inc, New York. 1994.

[8] Myers, T.G., Hall, R.W., Savage, P.H., Gaskell, P.H. The transition region of elastohydrodynamic lubrication. Proc. Roy. Soc. Lond. 1991;A432:467-479.

[9] Vicente J. de, Stokes, J.R., Spikes, H.A. The frictional properties of Newtonian fluids in a rolling-sliding soft-EHL contact. Trib. Lett. 2005;20:273-285.

[10] Jeng, Y.R., Hamrock, B.J., Brewe, D.E. Piezoviscous effects in nonconformal contacts lubricated hydrodynamically. ASLE Trans. 1986;30:452-464.

[11] Hamrock B.J., Dowson D. Elastohydrodynamic lubrication of elliptical contacts for materials of low elastic modulus. 1-Fully flooded conjunction. NASA TN D-8528, 1977. 
[12] Hooke, C.J. Calculation of clearances in soft point contacts. Trans. ASME J. of Trib. 1988;67-173.

[13] Hooke, C.J. The elastohydrodynamic lubrication of elliptical point contact operating in the elastic isoviscous region. Proc. I.Mech.E. 1995;J209:225-234.

[14] Cameron, A., Gohar, R. Theoretical and experimental studies of the oil film in lubricated point contact. Proc. Roy. Soc. Lond. 1966;A291:520-536.

[15] Gohar, R. Oil film thickness and rolling friction in elastohydrodynamic point contact. Trans. ASME. J. Lub. Tech. 1971;93:371-382.

[16] Foord, C.A., Hammann, W., Cameron, A. Evaluation of lubricants using optical elastohydrodynamics. ASLE Trans. 1968;11:31-43.

[17] Koye, K.A., Winer, W.O. An experimental evaluation of the Hamrock and Dowson minimum film thickness equation for fully flooded EHD point contacts. Trans. ASME J. of Trib. 1981;103:284-294.

[18] Smeeth, M. Spikes, H.A. The influence of slide/roll ratio on the film thickness in EHD contact operating in the mixed lubrication regime. Proc. 22nd Leeds/Lyon Symposium on Tribology, The Third Body Concept: Interpretation of Tribological Phenomena, Lyon, Sept. 1995, 695-703, ed. D. Dowson et al., publ. Elsevier, Amsterdam. 1996.

[19] Crook, A.W. The lubrication of rollers. Phil. Trans. Roy. Soc. Lond. 1958;A250:387-409.

[20] Jablonka, K., Glovnea, R., Bongaerts, J. Evaluation of EHD films by electrical capacitance. J. Phys. D Appl Phys. 2012;45:385301.

[21] Sibley, L.B., Orcutt, F.K. Elastohydrodynamic lubrication of rolling contact surfaces. ASLE Trans. 1961;4:234-249.

[22] Ting, L.L. Development of a laser fluorescence technique for measuring piston ring oil film thickness. Trans. ASME J. of Trib. 1980;102:165-170.

[23] Myant, C., Reddyhoff, T., Spikes, H.A. Laser-induced fluorescence for film thickness mapping in pure sliding lubricated, compliant, contacts. Trib. Intern. 2010;43:1960-1969.

[24] Zhang, J., Drinkwater, B.W., Dwyer-Joyce, R.S. Acoustic measurement of lubricant-film thickness distribution in ball bearings. J. Acoust. Soc. Am. 2006;119:863-871.

[25] Foord, C.A., Wedeven, L.D., Westlake, F.J., Cameron, A. Optical elastohydrodynamics. Proc. I.Mech.E. 1969;184:487-505. 
[26] Gohar, R., Cameron, A. Optical measurement of oil film thickness under elastohydrodynamic lubrication. Nature. 1963;200:458-459.

[27] Roberts, A.D., Swales, P.D. The elastohydrodynamic lubrication of a highly elastic cylindrical surface. J. Phys. D. Appl. Phys. 1969;2:1317-1327.

[28] Roberts, A.D., Tabor, D. The extrusion of liquids between highly elastic solids. Proc. Roy. Soc. Lond. 1971;A325:323-345.

[29] Roberts, A.D., Tabor, D. Fluid film lubrication of rubber - an interferometric study. Wear 1968;11:163-166.

[30] McClune, C.R., Tabor, D. An interferometric study of lubricated rotary face seals. Trib. Intern. 1978;219-227.

[31] Jin, Z. M., Dowson, D., Fisher, J., Rimmer, D., Wilkinson, R., Jobbins, B. Measurement of lubricating film thickness in low elastic modulus lined bearings, with particular reference to models of cushion form bearings for total joint replacements: Part 1: steady state entraining motion. Proc. I.Mech.E. 1994;J208:207-212.

[32] Myant, C., Fowell, M, Spikes. H.A., Stokes, J.R. An investigation of lubricant film thickness in sliding compliant, contacts. Trib. Trans. 2010;53:684-694.

[33] Hidrovo, C.H., Hart, D.P. Emission reabsorption laser induced fluorescence (ERLIF) film thickness measurement. Measurement Sci. \& Techn. 2001;12:467-477.

[34] Myant, C., Reddyhoff, T, Spikes, H.A. Laser-induced fluorescence for film thickness mapping in pure sliding lubricated, compliant, contacts. Trib. Intern. 2010;43:1960-1969.

[35] Fowell, M.T., Myant, C., Spikes H.A., Kadiric, A. A study of lubricant film thickness in compliant contacts of elastomeric seal materials using a laser induced fluorescence technique. Trib. Intern. 2014;80:76-89.

[36] Gaman, I.D.C., Higginson, G.R., Norman, R. Fluid entrapment by a soft surface layer. Wear. 1974;28:345-352.

[37] Johnson, K.L. Contact Mechanics, Reprint Edition, Cambridge University Press, Cambridge. 2008.

[38] Guegan, J., Kadiric, A., Spikes, H.A. A study of the lubrication of EHL point contact in the presence of longitudinal roughnesses. Trib. Lett. 2015;59:22. 
[39] Foord, C.A., Wedeven, L.D., Westlake, F.J., Cameron, A. Optical elastohydrodynamics. Proc. Inst. Mech. Eng. 1969;184:487-505.

[40] Johnston, G.J., Wayte, R., Spikes, H.A. The measurement and study of very thin lubricant films in concentrated contacts, Tribology Transactions, 1991;34:187-194.

[41] Hamrock, B.J., Dowson, D. Elastohydrodynamic Lubrication of Elliptical Contacts for Materials of Low Elastic Modulus I-Fully Flooded Conjunction, J. of Lubrication Tech, 1978;100:236-245. 